
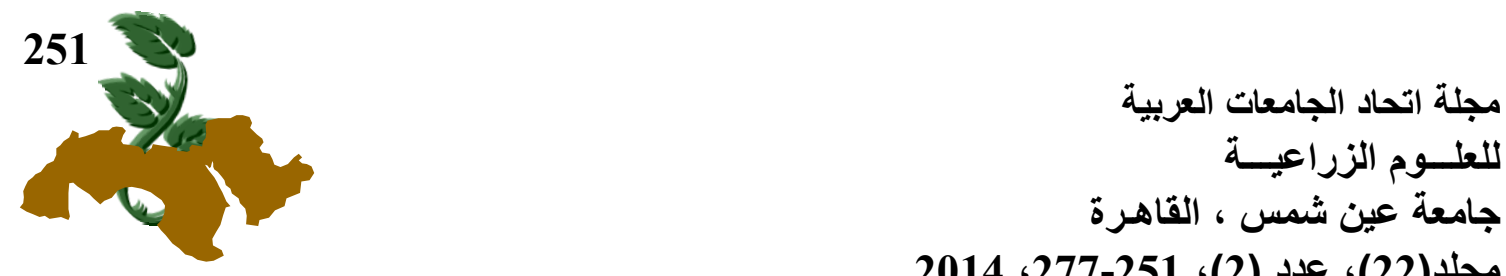

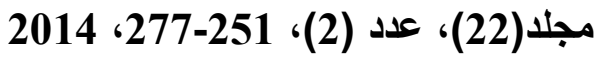

قياس أثر تطبيث نُظم الري المُختلفة على الكفاعة الإنتاجية والاقتصادية لأهم محاصيل

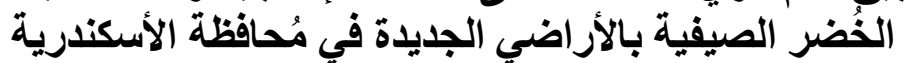

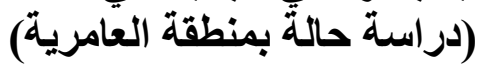

أحمد محمد فراج قاسم1 ـ تامر محمد عبد الصادق السنتريسي1 ـ محمد فوزي محمد الاناصوري 1

[20] 1- معهد بحوث الاقتصاد الزراعي- مركز البحوث الززاعية - جيزة ـ مصري الئر

المنهجية الحدودية والتي تعتمد على ما يُعرف بدالة

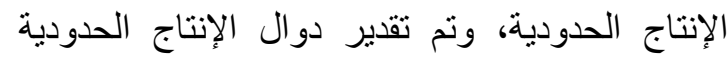
بطريقة التحليل الحدودي العشو ائي لتقدير دو ال الإنئ الإنتاج

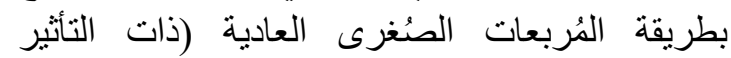
الثابت)، وطريقة أعظم احتمال ممكن (ذات التئن التأثثر

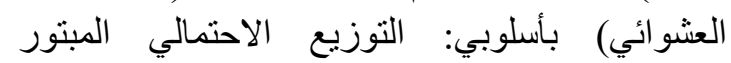

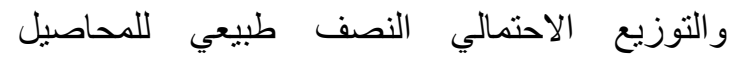

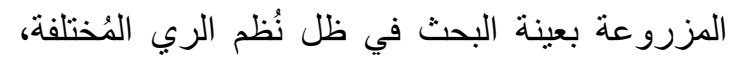

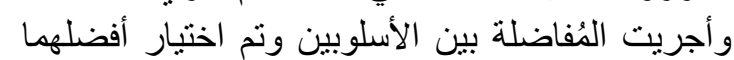

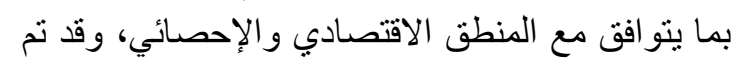

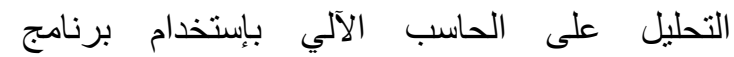
FRONTIER (Version 4.1c) البرنامج على توزيعين وهما: التوزيع الاحتمالي للخطأ

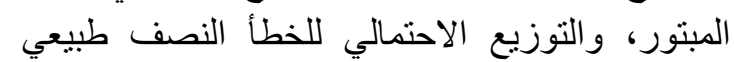

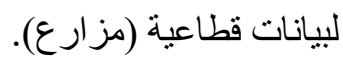
واعتمد البحث في إجرائه على البيانات الميدانية

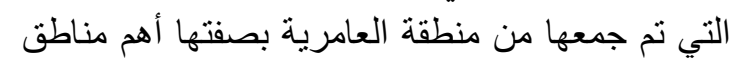

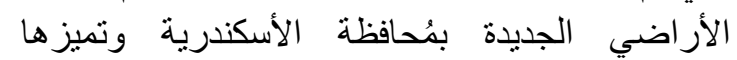

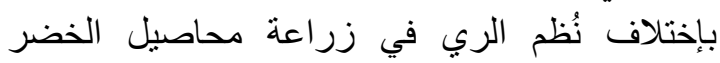
الصيفية، وقد تم إختيار مُحافظة الأسكندرية حيث نُمثئل

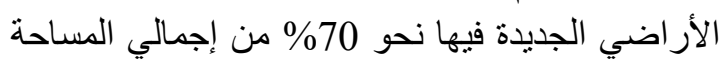

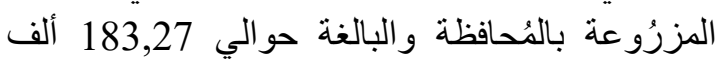

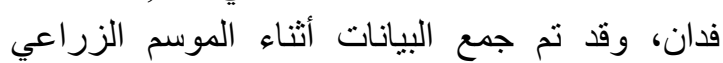

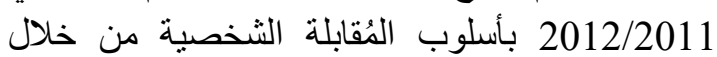
إستمارة إستبيان لعينة طبقية بلغ قوامها 100 مُز ارعاً
الكلمات الدالة: المنهج الحدودى، التوزيع الاحتمالى التى التوبي

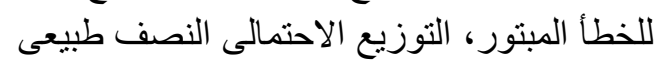

$$
\text { الموجز }
$$

استهدف البحث بصفة رئيسية قياس أثر تطبيث نُظم الكما

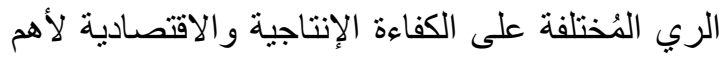

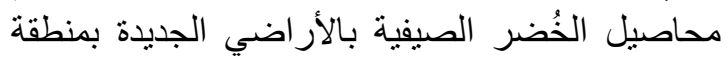

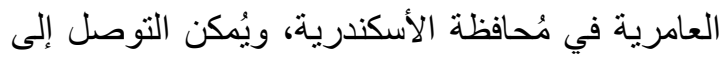

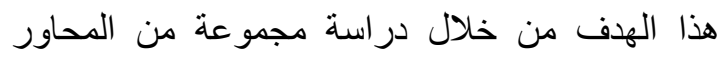

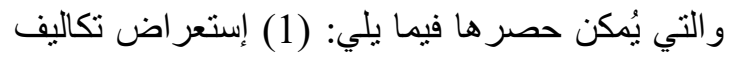

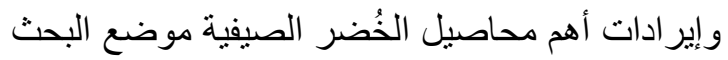

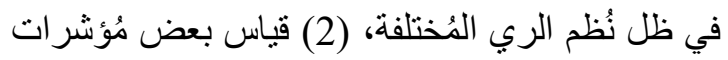

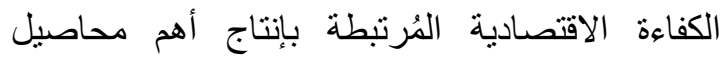

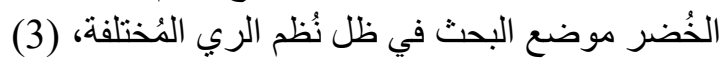

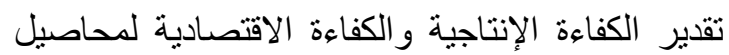

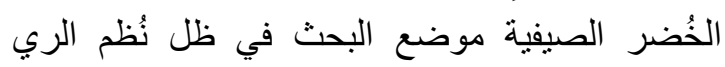

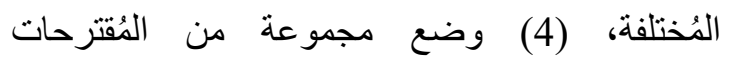

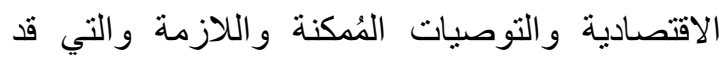

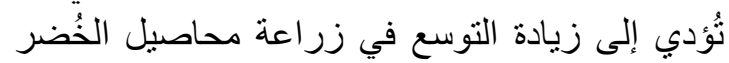

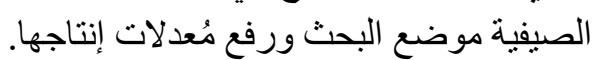

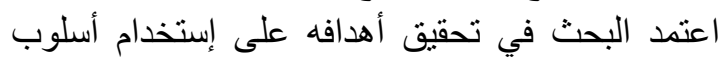

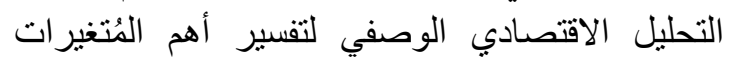

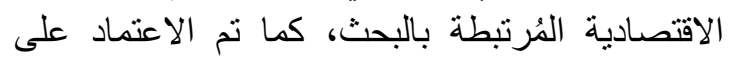

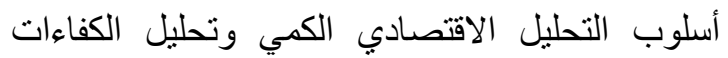

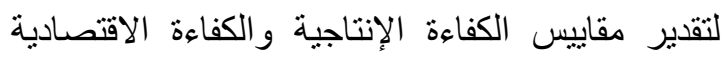
لمحاصيل الخضر موضع البحث، وذللك بإستخدام الإنة

(سلم البحث فى 2 يونيو 2014) (الموافقة على البحث فى 16 يونيو 2014) 
تُعتبر كفاية المياه من حيث الكم والكيف من القضايا

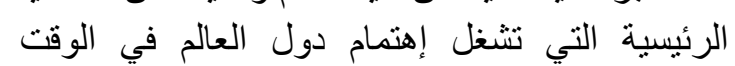

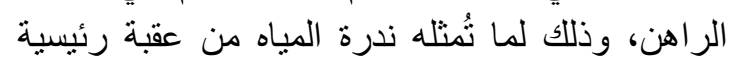

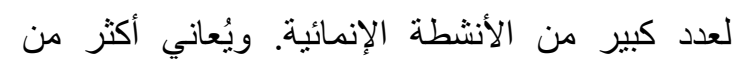

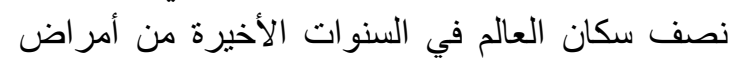

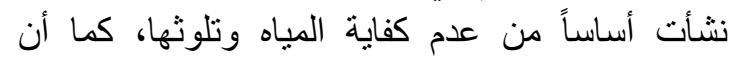

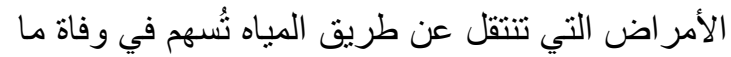

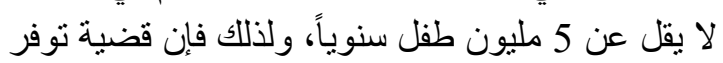

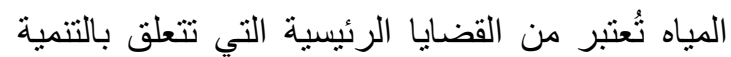

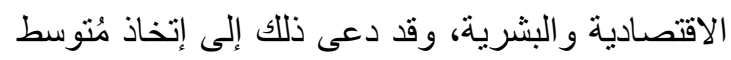
نصيب الفرد من المياه مُؤشر اً من المُؤشر الثرات الرئئيسية لدرجة التنمية في أي دولة. وقد نشأت مُشنكلة المياه

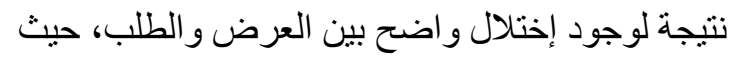

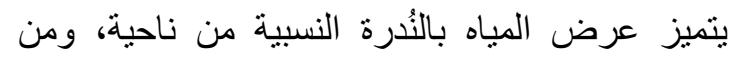

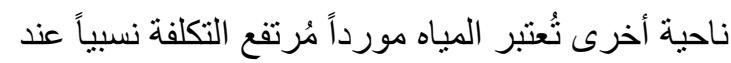

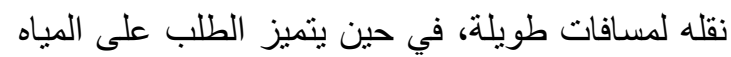
بالزيادة المُستمرة نتيجة النُمو الكبير في علئ فدد السكان

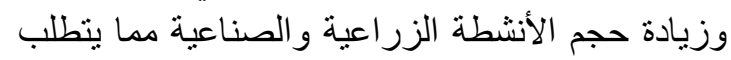

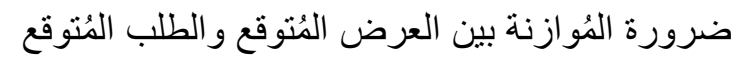

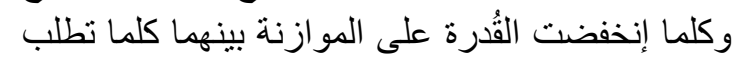

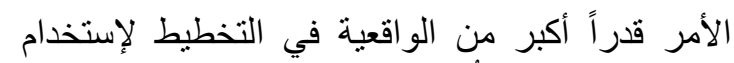

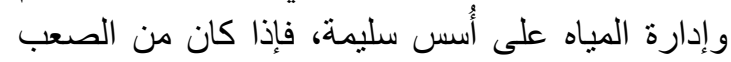
زيادة عرض المياه والزيادة في الطلب من الصعب الطب الطبان التحكم فيها لأنها تتشأ بسبب طبيعة التيادة في التطور الاقتصادي من التبادي

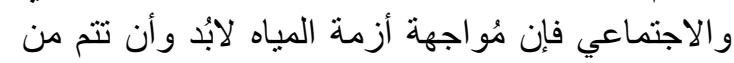

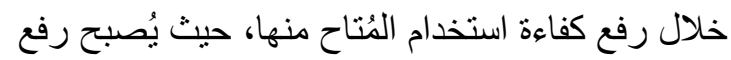

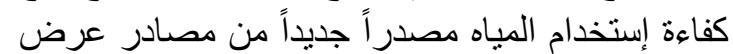

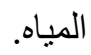

\section{مُشكلة البحث}

تتوجه الزراعة المصرية في الآونة الأخيرة إلى لئ

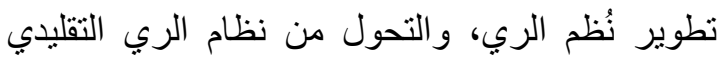

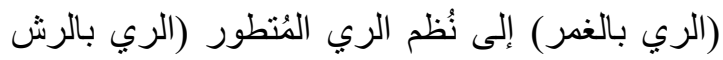

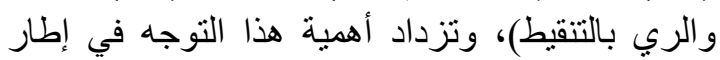

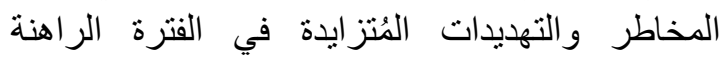

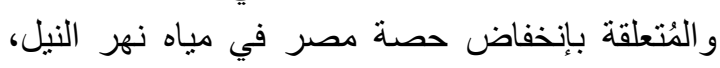

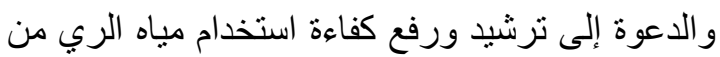

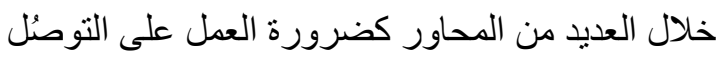
لكُختلف الطُرق والأساليب المُمكنة للإستخدام الأمثل الئل
يقومون بزر اعة أهم محاصيل الخُضر الصيفية موضع البحث و المُتمثلة في كلٍ من الكوسة و الفلفل و الباذنجان

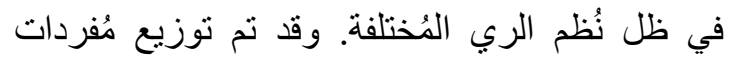

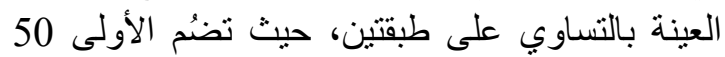

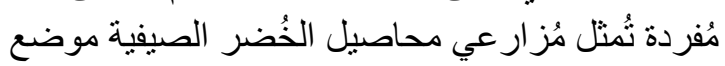

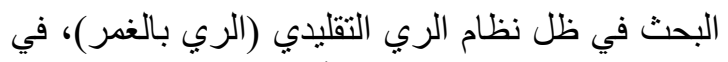

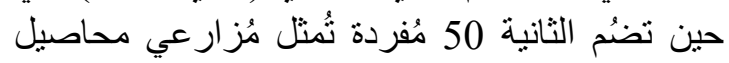
الخُضر الصيفية موضع البحث في ظل نظامي الري المُتطور (الري بالرش أو بالتنقيط).

المقدمة 
Stochastic Frontier Analysis (S.F.A) دوال الإنتاج بطريقة المُربعات الصُغرى العادية Ordinary Least Squares (O.L.S)

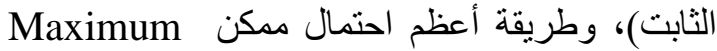
Likelihood Estimator (M.L.E) العشوائي) بأسلوبي: التوزيع الاحتمالي المبتور Truncated Distribution Half-Normal Distribution النصف طبيعي

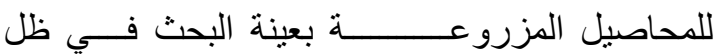

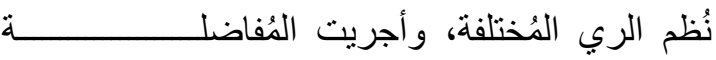

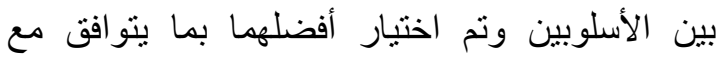

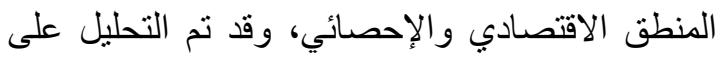
FRONTIER الحاسب الآلي بإنتخدام برنامج

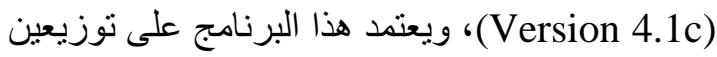

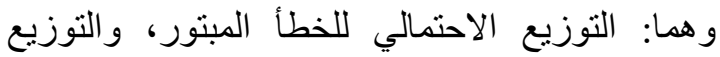
الاحتمالي للخطأ النصف طبيعي لبيانات قطاعية لإنية

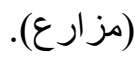

مصادر البيانات وإختيار العينة

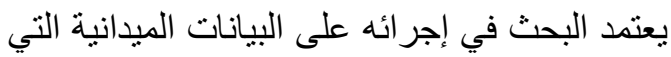

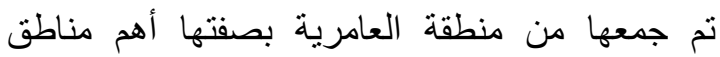

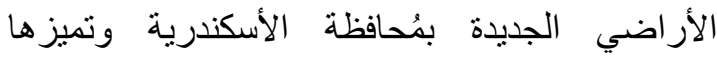

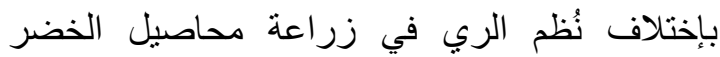

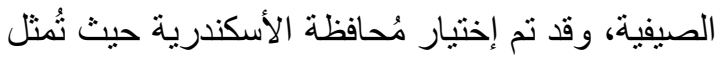
الأراضي الجديدة فيها نحو 70\% من من إجمالي المساحة

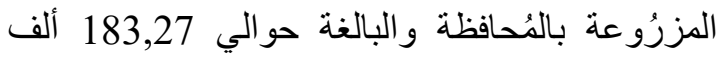

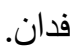
وقد تم جمع البيانات أثناء الموسم الزراعي 2012/2011 بأسلوب اليُقابلة الثخصية من خلال إستمارة إستبيان Questionnaire لعينة طبقية بلغ

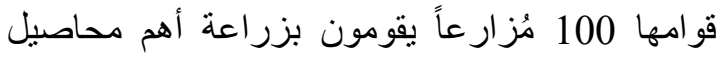

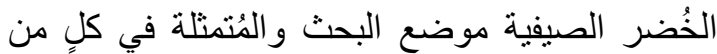

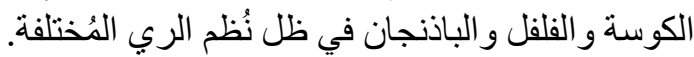

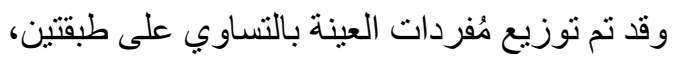

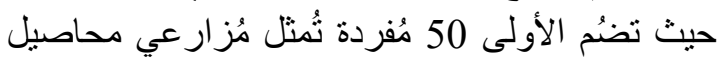

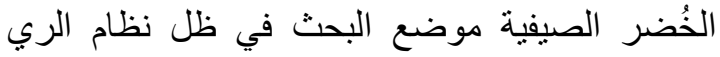

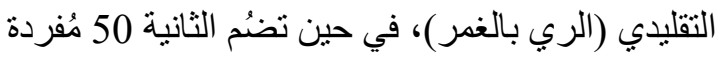

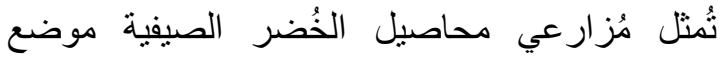
البحث في ظل نظام الري الُُتطور (الري بالرش أو أو
للمياه بما يتناسب مع الاعتبارات القومية والفردية

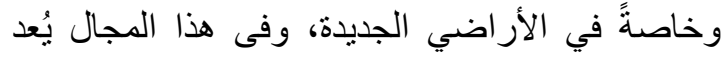

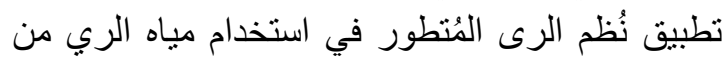
أهم الوسائل المُستخدمة لرفع كفاءة إستخدام المياه

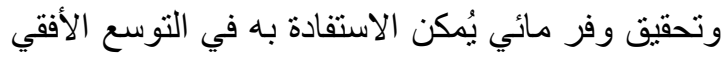

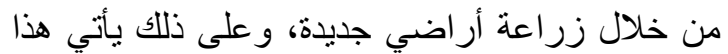

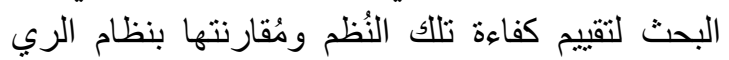

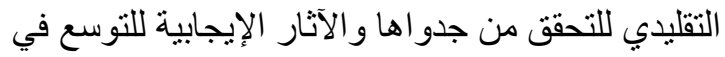
استخدامها في الزر اعة المصرية.

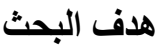

يستهدف البحث بصفة رئيسية قياس أثر تطبيق نُظم الري المُختلفة على الكفاءة الإنتاجية و الاقتصادية لأهم

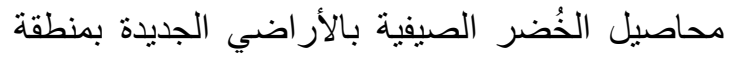

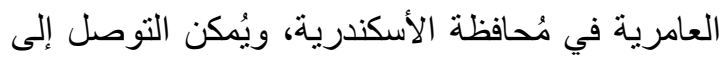

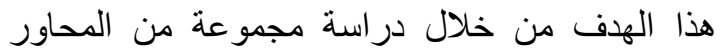

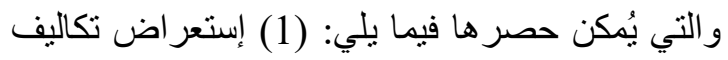

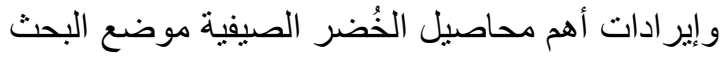

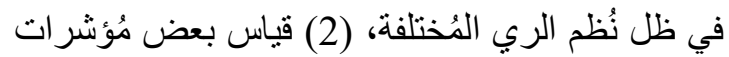

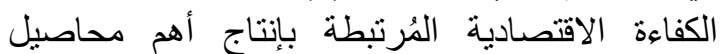

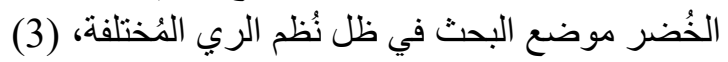

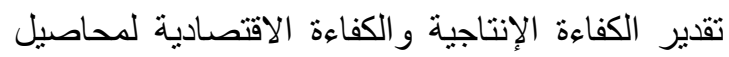

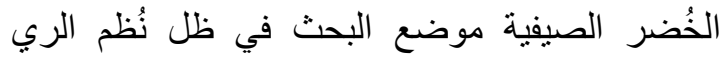

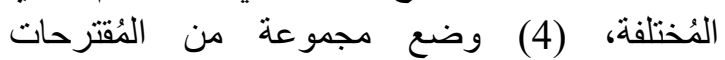

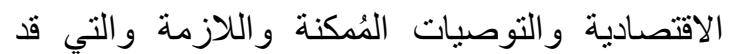

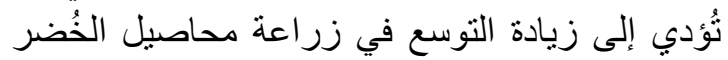
الصيفية موضع البحث ورفع مُعدلات إنتاجها.

$$
\text { أسلوب البحث }
$$

بعتمد البحث في تحقيق أهدافه على إستخدام أسلوب الفي

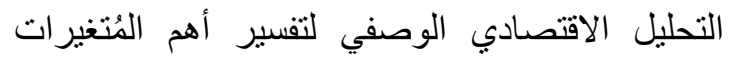

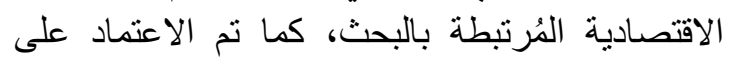

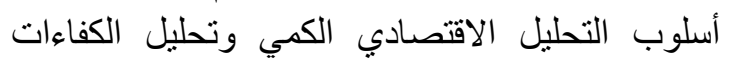
لتقدير مقاييس الكفاءة الإنتاجية والكفاءة الاقتصادية لمحاصيل الخضر موضع البحث، وذللك بإستخدام المنهجية الحدودية Frontier Approach و التي تعتمد Frontier على ما يُعرف بدالة الإنتاج الحدودية Production Function الحدودية بطريقة التحليل الحدودي العشوائي دوالي 
ويعيبه أن تقدير ات الكفاءات تتأثز بثكل كبير بأخطاء

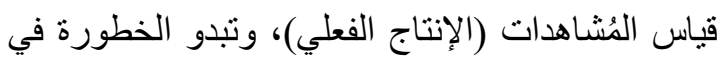

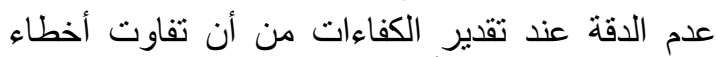

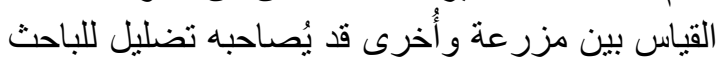

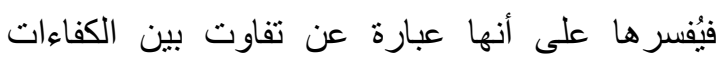
نفسها.

ثُانياً: المنهج الحُدودي الاحتمالي: ويُستخدم هذا المنهج في تقدير الكفاءات باستخدام دالة الإنتاج الحُدودية، الحئه

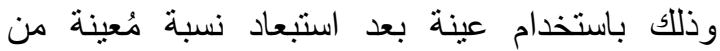

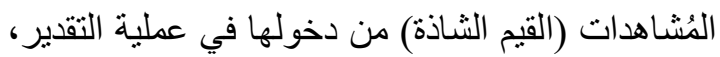
وتعتمد هذه النسبة في تقديرها على ظروف الفئ البحث،

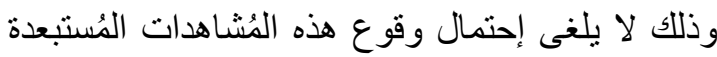

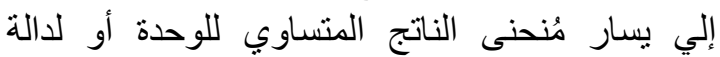

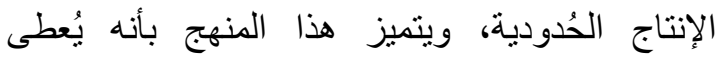

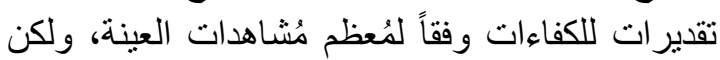

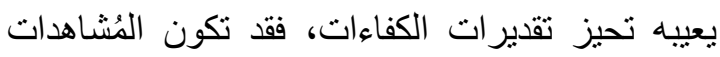

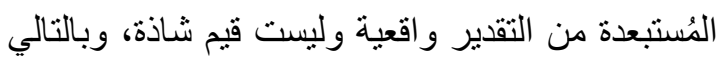
عدم توصيف دالة الإنتاج بشكل دقيق.

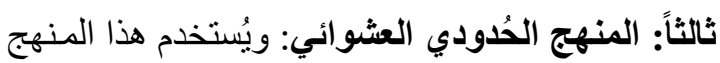

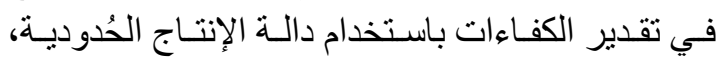

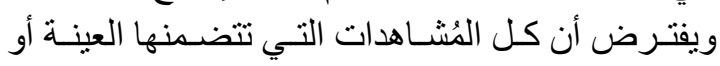

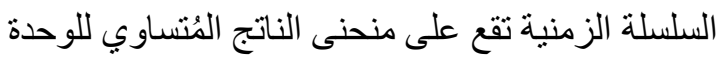
أو أعلى منه، ويستند هذا المنهج إلى أن حد الخطأ النَّأ الكُلي

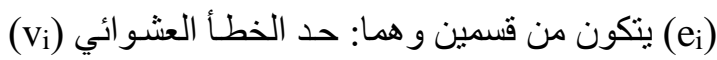

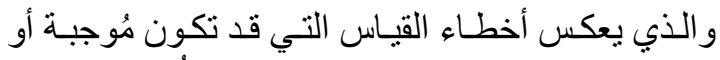

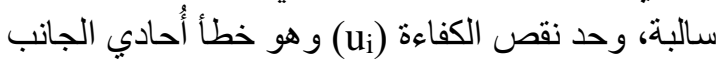

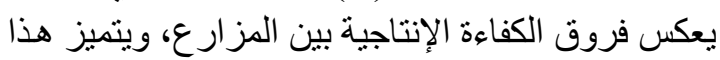

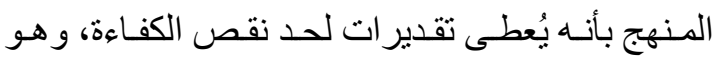
بذللك يفصله عن حد الخطأ العشو ائي للتقدير مما يُتيح

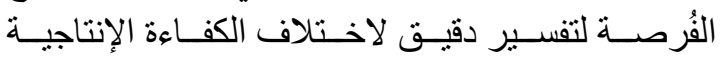

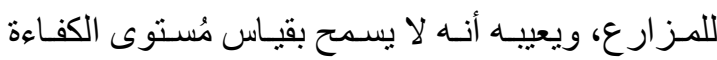

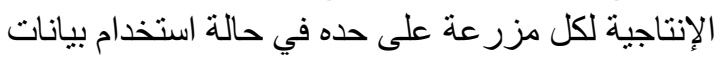

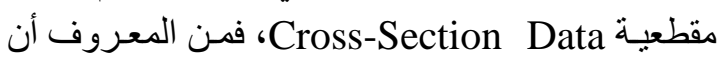

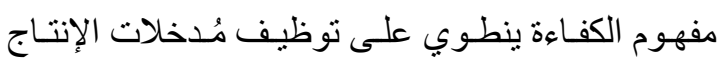

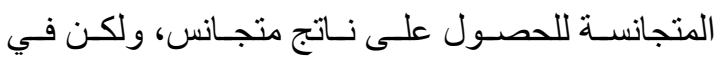

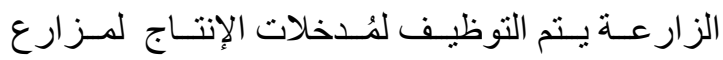

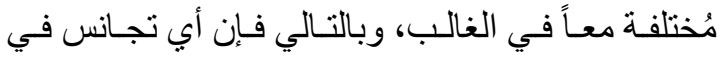
عناصر الإنتاج لا يُحقق الإنتاج الأمثل من الئدان التحلات
بالتنقيط)، وقد تبين أن الطبقة المُستخدمة لنظام الري

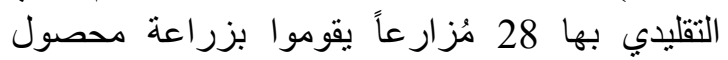

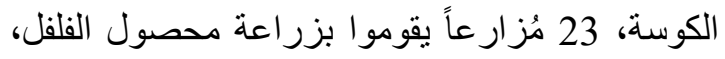

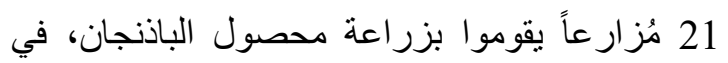

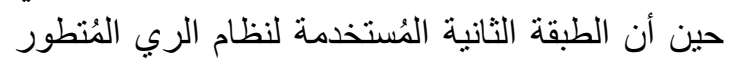

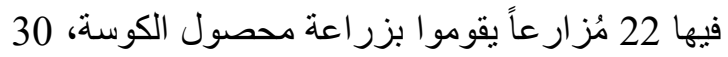

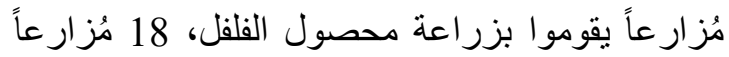

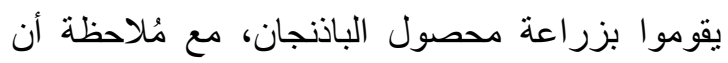

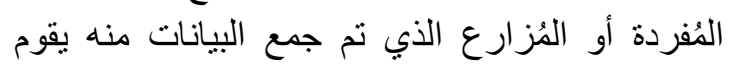

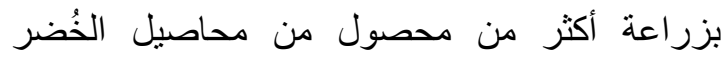

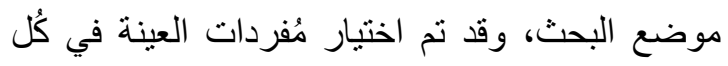

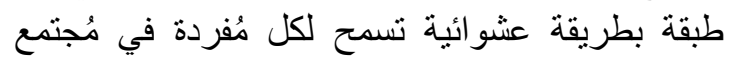

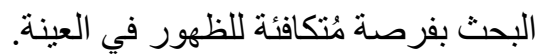
كما اعتمد البحث أيضاً على البيانات الثئة الثانوية

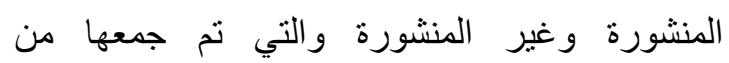
مصادر ها الرسمية مثل: وزارة الزئورة الزراعة واستصلاح الأراضي، وزارة الموارد المائية والرية الري، واعل ومديرية

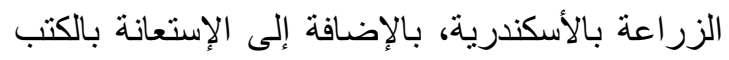

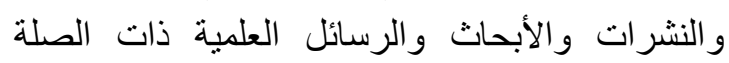

$$
\text { بموضوع البحث. }
$$

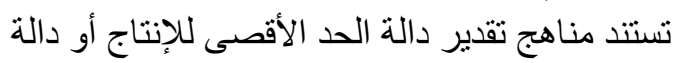

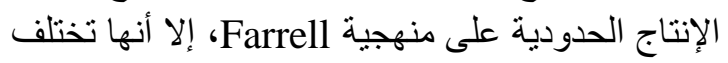
في التفاصيل كإسقاط فرض التجاجس الإنس الخطي لدالة الإنة

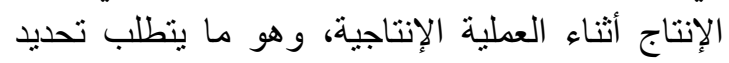

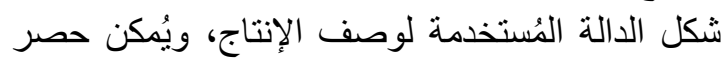

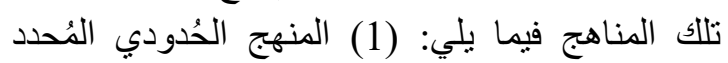
(2) ‘Deterministic Frontier Approach المنهج الحُدودي الاحتمالي Probabilistic Frontier Approach Stochastic Frontier Approach إستعر اض كل منهج منها فيما يلي:

أولاً: المنهج الحُدودي المُحدد: ويفترض هذا المنهج

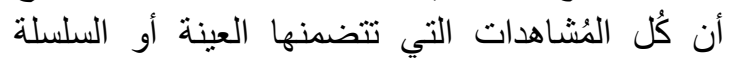

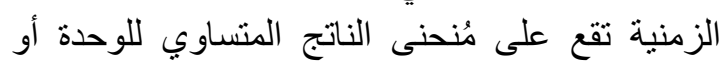

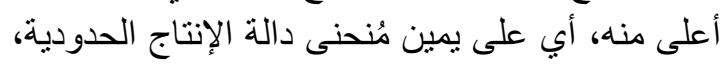

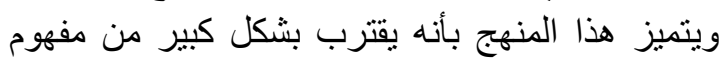
دالة الإنتاج كإطار خارجي يُخلف المُشـاهدات الفعلية، 
طبيعي أو الآسي أو جاما)، لأنه توزيع مبتور أي (u)

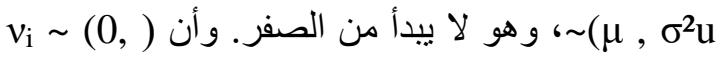

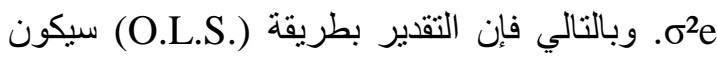

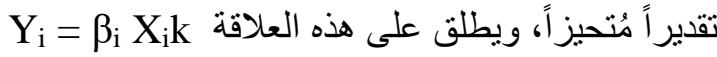
علاقة حدودية، أما الحدودية العشو ائية فنُطلق على u الكُمثلة لحد نقص الكفاءة Controlled، و عند

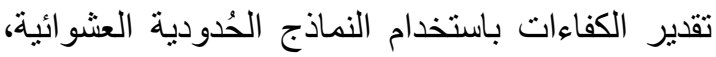

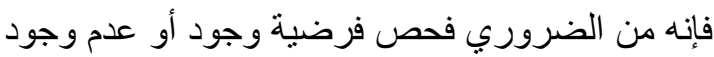
التأثير العشو ائي.

إختبار التأثير العثوائي: وهو إختبار لمعرفة تأثثير

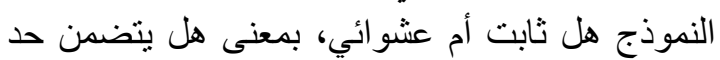

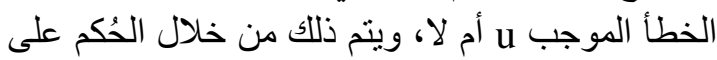

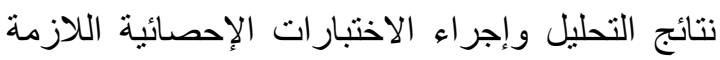
و التي تتمثل فيما يلي:

الاختبار الكُلي: وهو إختبار وجود تأثثر عشوائي أم لا، ويتمثل الفرض العدمي فيما يلي:

$$
H_{0}: b_{1}=b_{2}=\ldots . . . b_{k}=0
$$

ويتم الكُفاضلة بين النماذج على أساس معيارين

(أ) الشرط الضروري: وهو اختبار نسبه جاما :Gamma Ratio Test $(\gamma)$ تتم الئفاضلة بين النماذج الحدودية العشو ائية على أساس معنوية ( 7 ) و وققاً لما يلي: $\gamma=0$ :Null Hypotheses 0 (1) الفرض العدمي

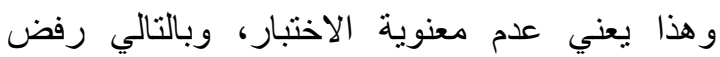

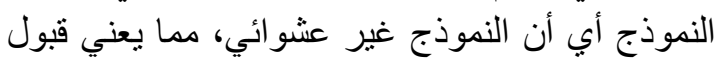

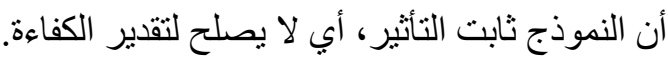
(2) الفرض البديل Alternative Hypotheses 0 النموذج العشو ائي لتقدير الكفاءة.

$$
\gamma=\sigma^{2} u / \sigma^{2}
$$

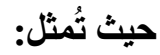
ү: التباين الر اجع لنقص الكفاءة إلى التباين الكُلي.
المُتلىى، ولذلك نشأ اختلاف بين المُخرجات المُخطط لها

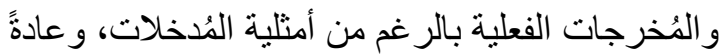

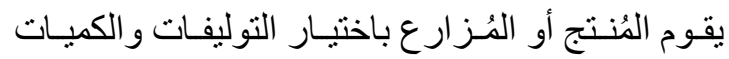

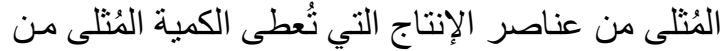

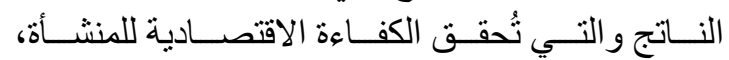

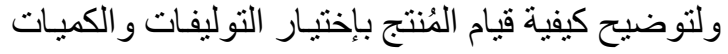

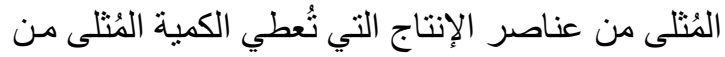

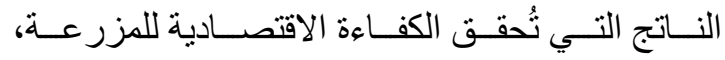

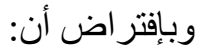

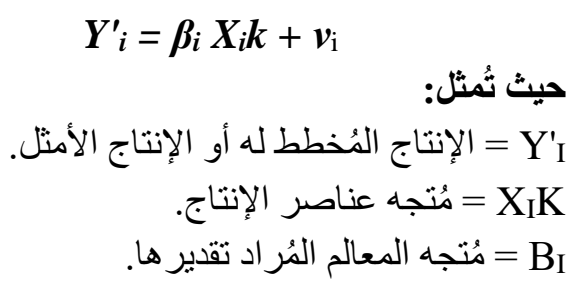
= vi $\mathrm{N} \sim\left(0, \sigma^{2} \mathrm{v}\right)$ 1, 2, 3,.... ع عدد اليُلاحظات = i إلا أنه في الحياة العملية والتطبيقية نجد أن كمية

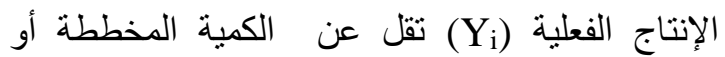

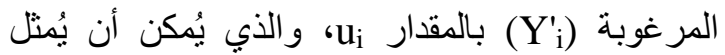

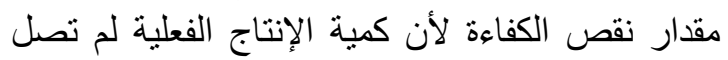

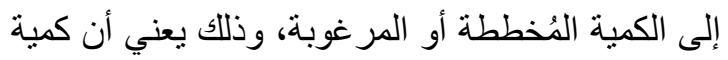

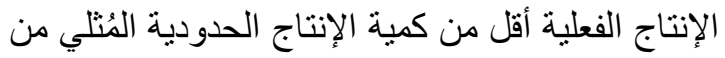

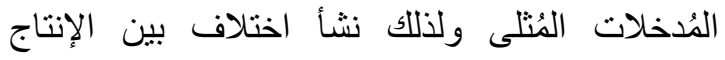
المُخطط و الإنتاج الفعلي.

$$
\begin{array}{r}
Y_{i}=Y^{\prime}{ }_{i}-u_{i} \\
Y_{\mathbf{i}}=\beta_{\mathbf{i}} \mathbf{X}_{\mathbf{i}}+v_{\mathbf{i}}-\mathbf{u}_{\mathbf{i}}
\end{array}
$$

$$
\text { ويُمكن أن تأخذ المعادلة (1) الصورة التالية: }
$$$$
\mathbf{Y}_{\mathbf{i}}=\boldsymbol{\beta}_{\mathbf{i}} \mathbf{X}_{\mathbf{i k}}+\mathbf{e}_{\mathbf{i}}
$$

$$
e_{i}=v_{i}-u_{i}
$$

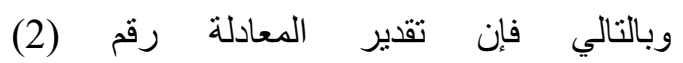

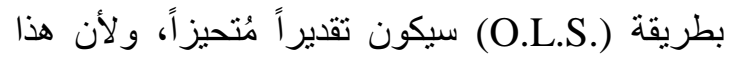

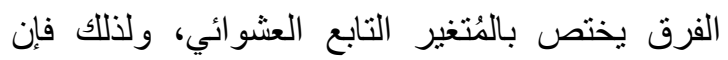

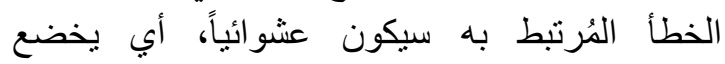

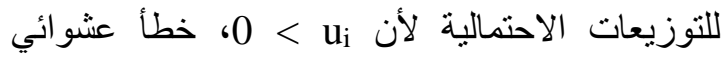

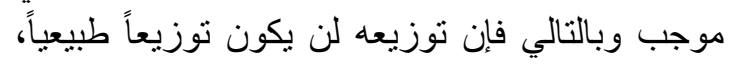

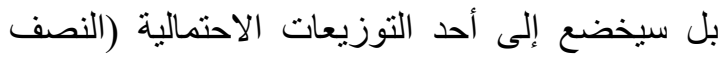




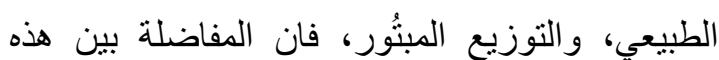

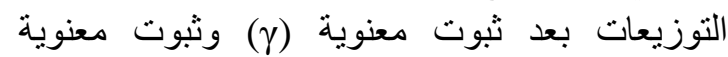
(L.R) المعنوينين. (L.R) ومن العرض السابق لمزايا وعيوب مناهج تقدير

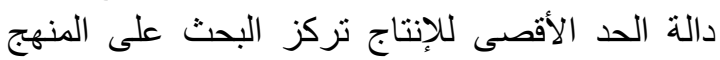

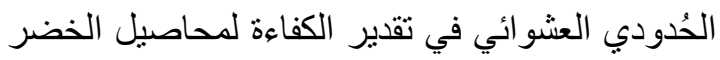

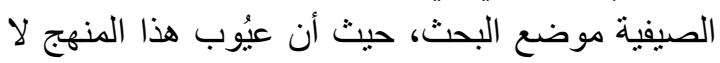

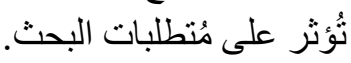

\section{نتائج البحث}

توصل البحث إلى مجموعة من النتائج المُرتبطة

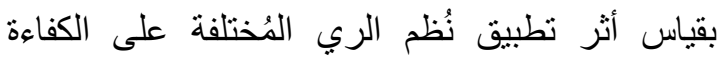

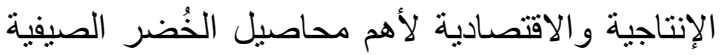

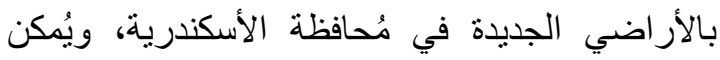

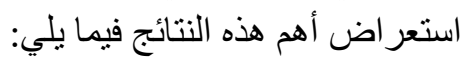

أولاً: تكاليف وإيرادات أهم محاصيل الخضر الصيفية

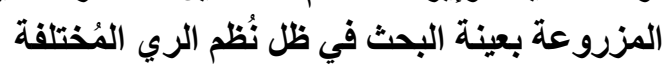

تتكون تكاليف أهم محاصيل الخُضر الصيفية المزروعة بعينة البحث في منطقة العامرية من الآتي:

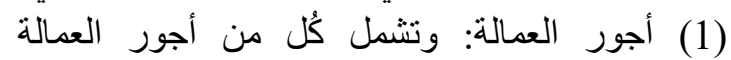

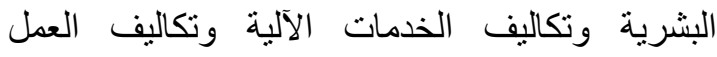

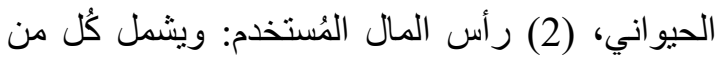

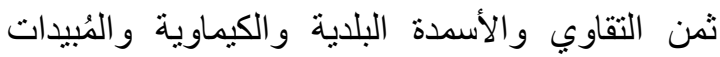

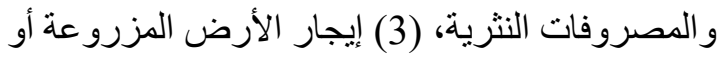

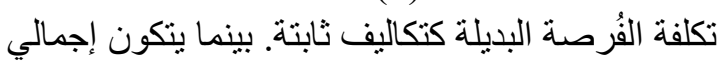

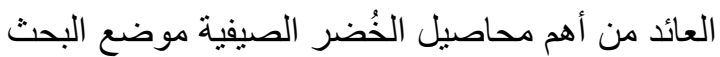

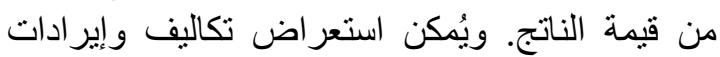

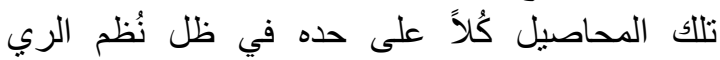

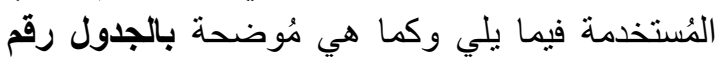

(1) تكاليف وإيرادات محصول الكوسة في ظل نُظم

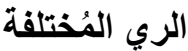

يتضح من البيانات الواردة في الجدول رقم (1)

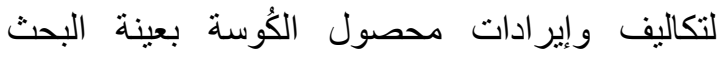
بمنطقة العامرية في مُحافظة الأسكندرية في ظل نُطن

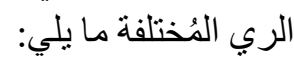

U

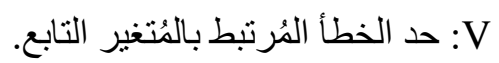
ومن خلال فحص معنوية جاما للنمُوذج العشو ائي، فانه توجد حالتين و هما:

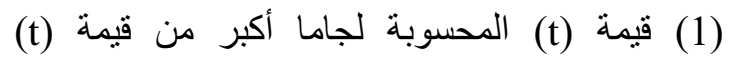
(1) الجدولية عند مُستوى 0,05 ودرجات حرية - (1) (1، فانه يتم رفض الفرض العند العدمي بأن النموذج ثابت التأثثر وقُبول الفرض البديل بوجود العشوائية، ويتم الإعتماد على النموذج المُقدر بطريقة (M.L.E)

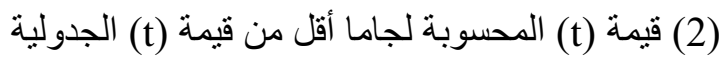

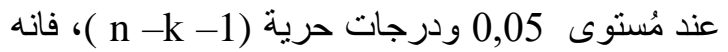

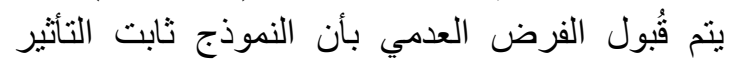
وغير عشوائي، ويتم الإعنماد على النموذج المُقدان بطريقة (O.L.S).

(ب) الثرط الكافي: وهو اختبار نسبه الاحتمال الأعظم :Likelihood Ratio Test (L.R)

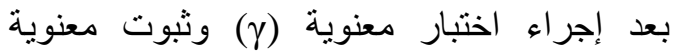

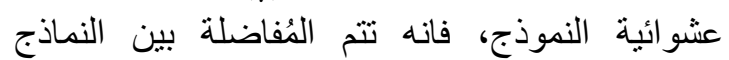

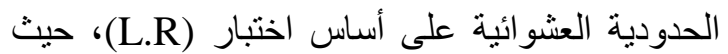
يفحص الاختبار الفرق بين قيمة دالة لو غاريتم التئم الاحتمال الأعظم (L.L.F) عند الفرض العدمي Ho.S.S (التقدير بطريقة O.L.S)، وقيمتها عند الفرض البديل

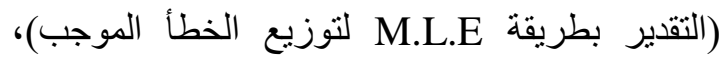
وتتمثل مُعادلة هذا الاختبار في الآتي:

$$
L . R=-2\left(\operatorname{Ln} H_{0}-\operatorname{Ln} H_{a}\right)=-2\left(L L H_{0}-L L H_{a}\right)
$$

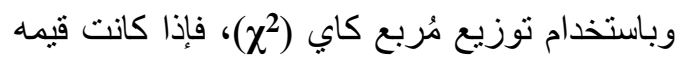

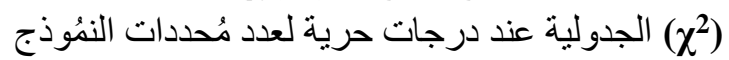

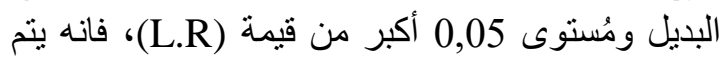
قُبول الفرض العدمي وهو عدم جدوى استخدام النموذج النقان

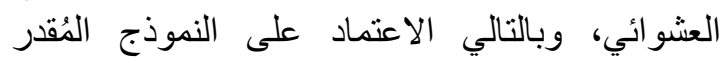
بطريقة (O.L.S) وبالتالي عدم جدوى فحص الألي الاختبار ات الجزئية.

المُقارنة بين نمُوذجين عشوائيين أو أكثر: إذا كانت

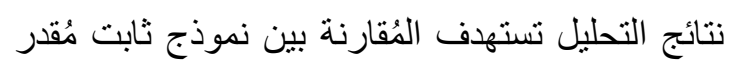

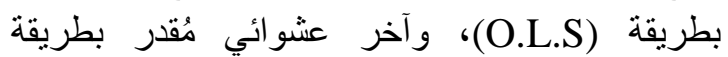
وكان هناك عدد من التوزيعات الاحتمالية لعنصر نقص الكفاءة الموجب مثل التوزيع النصف التوزئ التئل 
(أ) تكاليف وإيرادات محصول الكوسة في ظل نظام المزروع في ظل نظام الري التقلبدي حوالي 1480

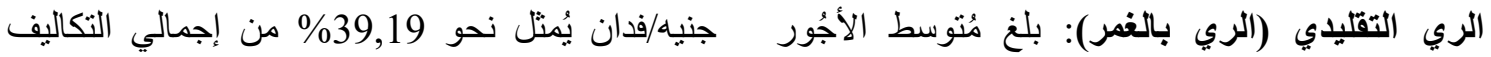

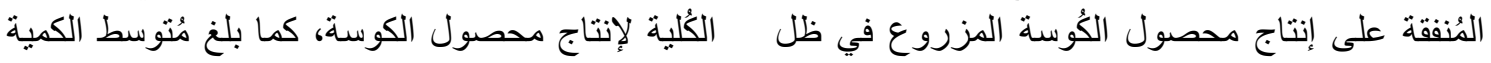

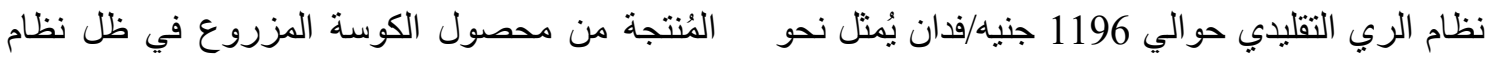

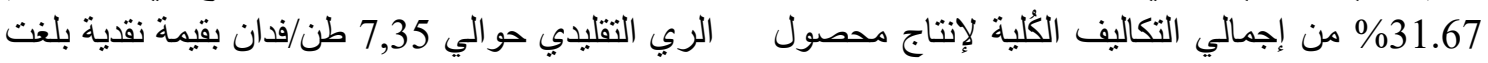

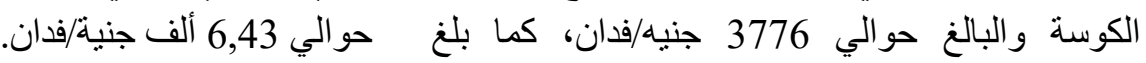
مُنتوسطر أس المال المُستخدم في إنتاج محصول الكُوسة 
جدول رقم 1. مُتوسط نكاليف و إيرادات محاصيل عينة البحث في ظل نُظم الري المُختلفة أثناء الموسم الزراعي 2012/2011

\begin{tabular}{|c|c|c|c|c|c|c|c|}
\hline \multicolumn{6}{|c|}{ محاصيل الخُضر الصيفية } & \multirow{3}{*}{ المُتنغير ات الاقتصـادية* } & \multirow{3}{*}{ ن امام الري } \\
\hline \multicolumn{2}{|c|}{ الباذنجان } & \multicolumn{2}{|c|}{ القلفل } & \multicolumn{2}{|c|}{ الكوسة } & & \\
\hline$\%$ & القيمة & $\%$ & القيمة & $\%$ & القيمة & & \\
\hline 40.09 & 1754 & 34.44 & 1465 & 31.67 & 1196 & أجور العمالة & \\
\hline 34.77 & 1521 & 39.70 & 1689 & 39.19 & 1480 & رأس المال المشتخدم & \\
\hline 74.86 & 3275 & 74.14 & 3154 & 70.87 & 2676 & التكاليف المُتغيرة & \\
\hline 25.14 & 1100 & 25.86 & 1100 & 29.13 & 1100 & (تكلفة الفرصة البديلة) & تقليدي \\
\hline 100 & 4375 & 100 & 4254 & 100 & 3776 & التكاليف الكُلية & \\
\hline - & 8.45 & - & 6.54 & - & 7.35 & كمية الناتج & \\
\hline - & 815 & - & 1125 & - & 875 & سعر الناتج & \\
\hline- & 6887 & - & 7358 & - & 6431 & إجمالي العائد & \\
\hline 39.81 & 1673 & 36.84 & 1492 & 32.42 & 1204 & أجور العمالة & \\
\hline 34.01 & 1429 & 36.00 & 1458 & 37.96 & 1410 & رأس المال المثتخذدم & \\
\hline 73.82 & 3102 & 72.84 & 2950 & 70.38 & 2614 & التكاليف المُتغيرة & \\
\hline 26.18 & 1100 & 27.16 & 1100 & 29.62 & 1100 & (تكلفة الفرصة البديلة) & مُنطور \\
\hline 100 & 4202 & 100 & 4050 & 100 & 3714 & التكاليف الكُلية & \\
\hline- & 8.94 & - & 7.06 & - & 7.84 & كمية الناتج & \\
\hline- & 815 & - & 1125 & - & 875 & سعر الناتج & \\
\hline - & 7286 & - & 7943 & - & 6860 & إجمالي العائد & \\
\hline
\end{tabular}

* أجور العمالة، رأس المال المُستخدم، التكاليف، الإيجار، و إجمالي العائد بالجنيه للفذان، اما كمية الناتج فبالطن للفدان، وسعر الناتج بالجنيه للطن. المصدر: جُمعت وحُسبت من البيانات الواردة باستمارة الاستبيان الخاصة بعينة البحث أثناء الموسم الزراعي 2012/2011.

الكمية المُنتجة من محصول الكوسة المزروع في ظل طل

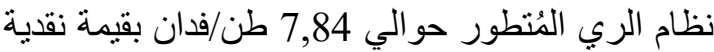
بلغت حو الي 6,86 ألف جنية/فدان.

(2) تكاليف وإيرادات محصول الفلقل في ظل نُظم الري المُختلفة

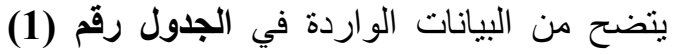

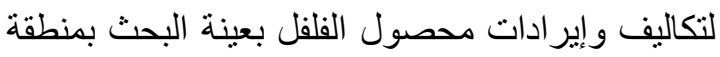

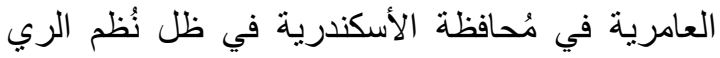

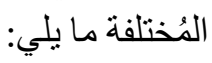

(ب) تكاليف وإيرادات محصول الكوسة في ظل نظامي

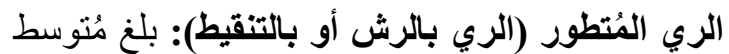

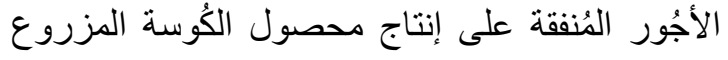
في ظل نظام الري المُنطور حوالي 1204 جنياه/فدان يُمثل نحو 32,42\% من إجمالي التكاليف الكُلية لإنتاج محصول الكوسة والبالغ حو الي 3714 جنيه/فدان، كما الئل

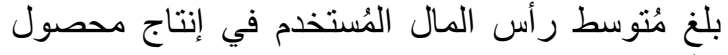

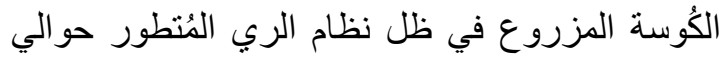

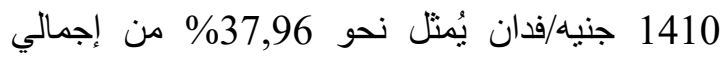
التكاليف الكُلية لإنتاج محصول الكوسة، كما بلغ مُنتوسط 
40,09 من إجمالي التكاليف الكُلبة لإنتاج محصول

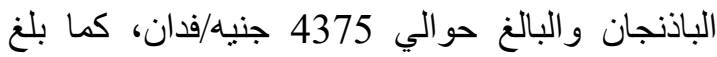
مُتنوسط رأس المال المُنستخدم في إنتاج محصول الباذنجان المزروع في ظل نظام الري التقليدي حوالي فئي

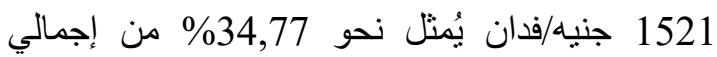

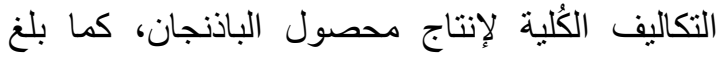

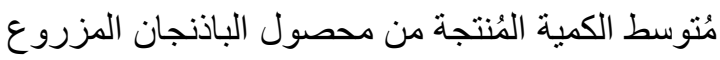
في ظل نظام الري التقليدي حوالي 8,45 طن/فدان بقيمة نقدية بلغت حو الي 6,89 ألف جنية/فدان.

(ب) تكاليف وإيرادات محصول الباذنجان في ظل الرئ

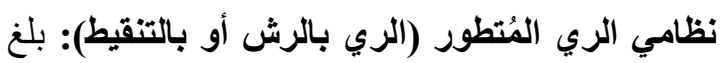

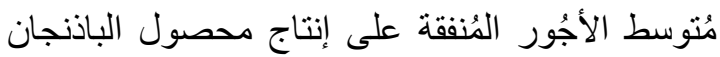
المزروع في ظل نظام الري المُنطور حواجي 1673 جنيه/فدان يُمثل نحو 39,81\% من إجمالي التكاليف الكُلية لإنتاج محصول الباذنجان و البالغ حو الي 4202

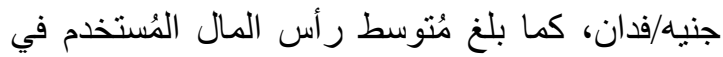

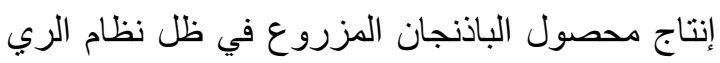

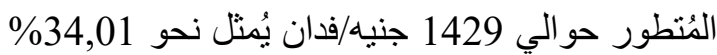

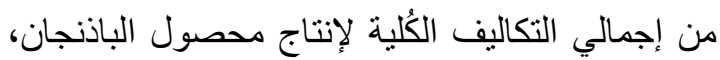

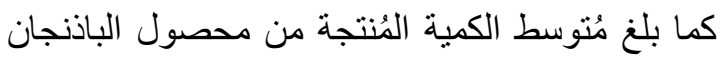
المزروع في ظل نظام الري المُنطور حو الي طن/فدان بقيمة نقدية بلغت حوالي

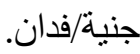

ثانياً: مُؤشرات الكفاءة الاقتصادية المُرتبطة بإنتاج أهم محاصيل الذضر الصيفية بعينة البحث في ظل نُظم الري المُختلفة

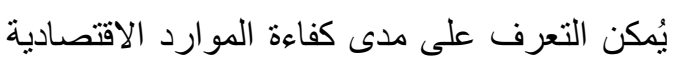

المُستخدمة في إنتاج أهم محاصيل الخضر الهرب الصيفية بعينة البحث المزرُوعة في ظل نظم الري التقليدي

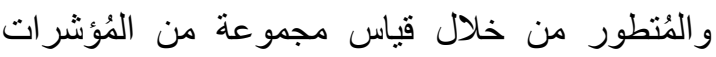

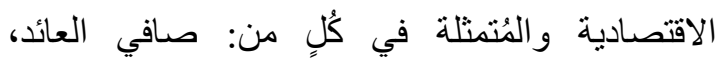

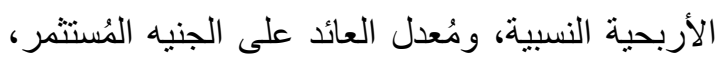
وتم إجراء اختبار تحليل التباين لمعرفة وجود أو عدم التماند وجود فروق معنوية في تلك المؤشرات في ظل نُظم
(أ) تكاليف وإيرادات محصول الفلقل في ظل نظام الري

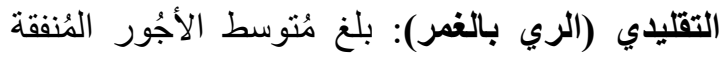

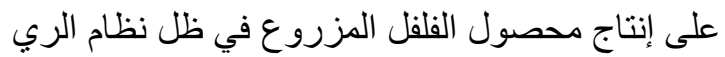

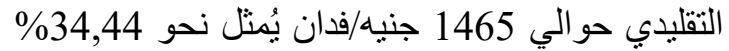
من إجمالي التكاليف الكُلية لإنتاج محصول الفئلئل الفلفل

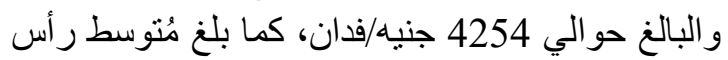
المال المُستخدم في إنتاج محصول الفلفل المزروع في فئلئ ظل نظام الري التقليدي حوالي 1689 جنيه/فدان يُمثنل نحو \%39,70\% من إجمالي التكاليف الكلية لإنتاج

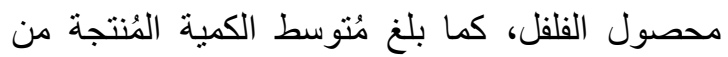

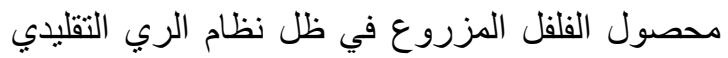

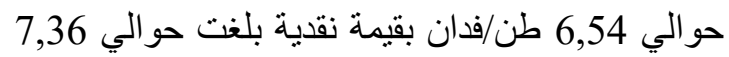

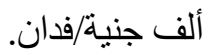

(ب) تكاليف وإيرادات محصول الفلقل في ظل نظامي

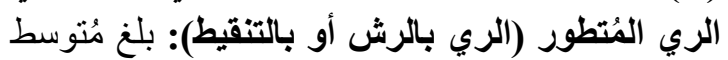

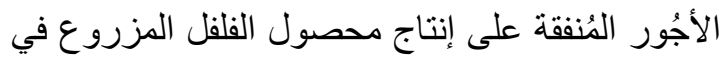
ظل نظام الري المُتطور حو الي 1492 جنيه/فدان يُمنّل

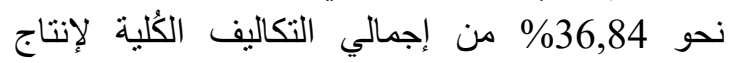
محصول الفلفل والبالغ حو الي 4050 جنيد/فدان، كما ليان

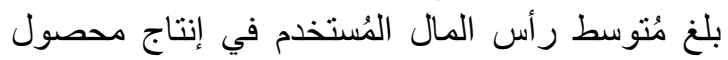

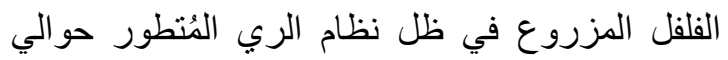

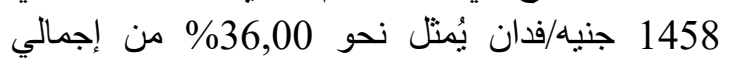
التكاليف الكُلية لإنتاج محصول الفلفل، كما بلغ مُنتوسط

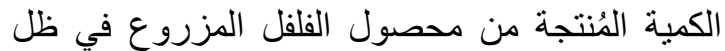
نظام الري المُنطور حو الي 7,06 طن/فدان بقيمة نقدية بلغت حوالي 7,94 ألف جنية/فدان.

(3) تكاليف وإيرادات محصول الباذنجان في ظل نُظم الري المُختلفة

يتضح من البيانات الواردة في الجدول رقم (1) لئنة لتكاليف وإيرادات محصول الباذنجان بعينة البحث البثان

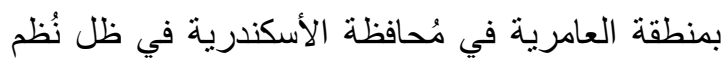

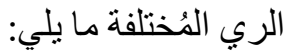

(أ) تكاليف وإيرادات محصول الباذنجان في ظل نظام

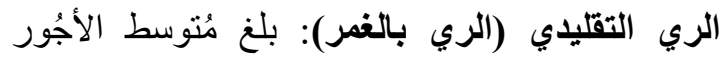

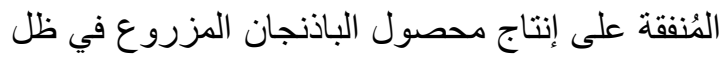

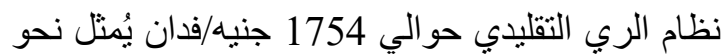


(F))، في حين بلغت الأربحية النسبية لمحصول الفلفل

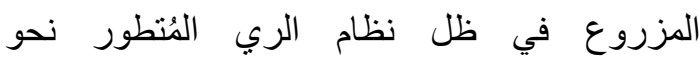

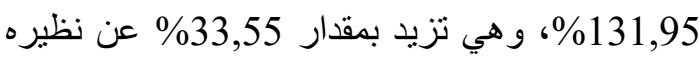

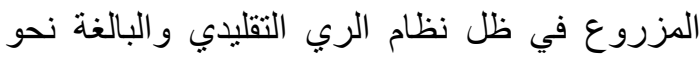

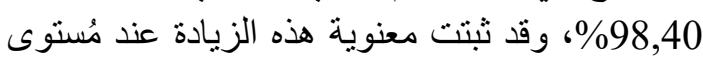

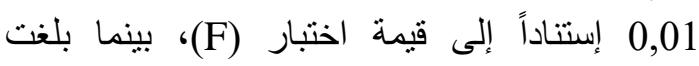

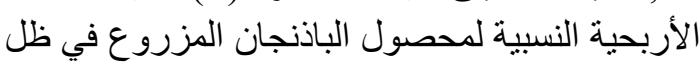

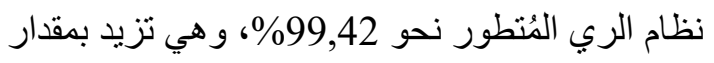

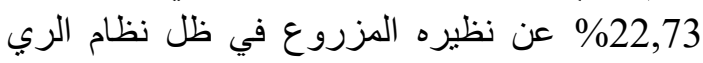

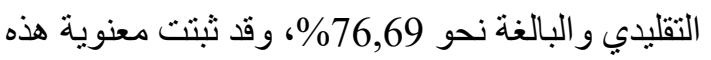
الزيادة عند مُسنوى 0,01 إستناداً إلى قيمة اختبار

مُعدل العائد على الجنيه المُستثمر: يتضح من رئن

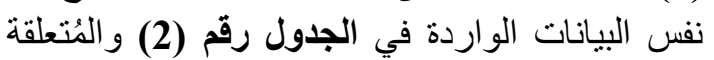
بُمؤشرات الكفاءة الاقتصادية لإنتاج أهم محاصيل

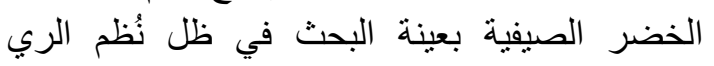

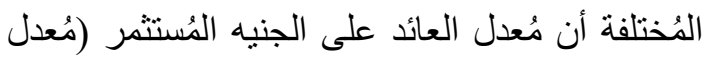

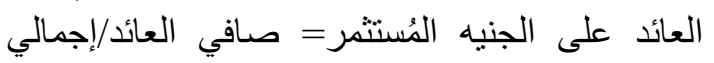
التكاليف) لمحصول الكوسة المزروع في ظل نظائ لنام

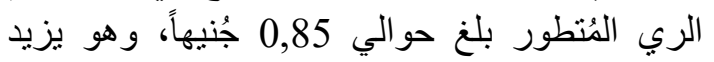

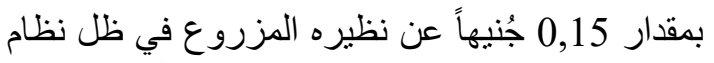

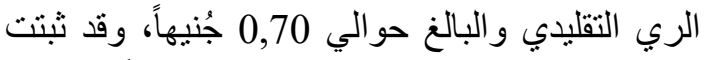

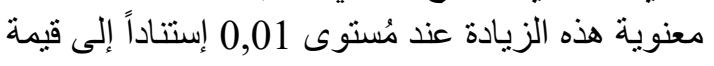

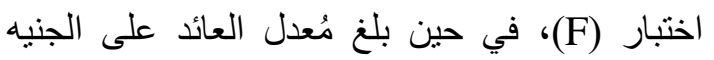

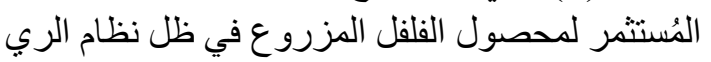

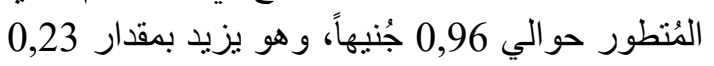

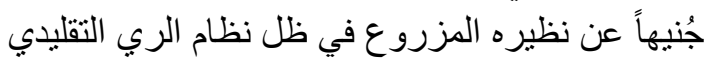

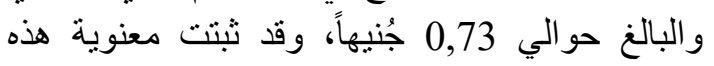

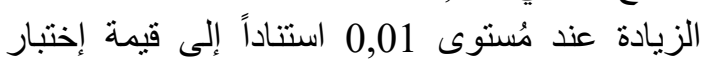

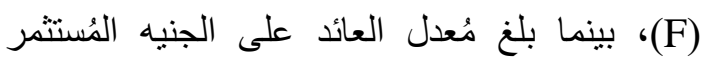

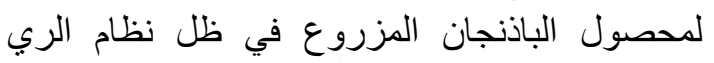
المُنطور حو الي 0,73 جُنيهاً، وهو يزئ فيد بمقدار

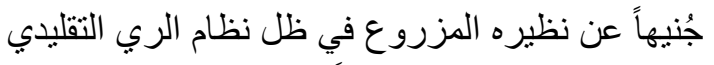

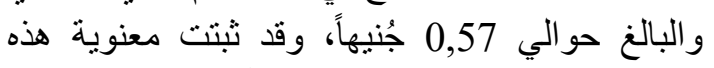
الزيادة عند مُستوى 0,01 إستناداً إلى قيمة اختبار
الري المُختلفة، ويُمكن استعر اض تلك المؤشرات على مُستوى محاصيل الخضر الصيفية موضع البحث ووفنقاً لنظم الري المُختلفة وذلك كما يلي:

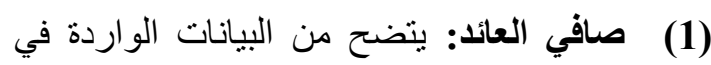

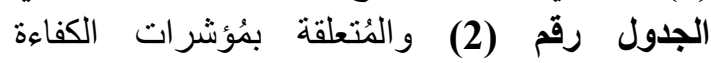

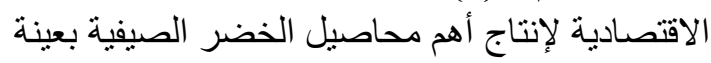
البحث في ظل نُظم الري الأختخلفة أن صافي العائد

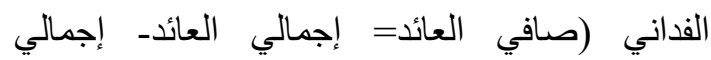

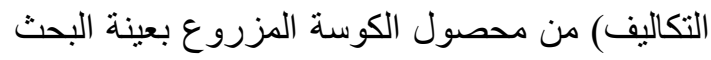

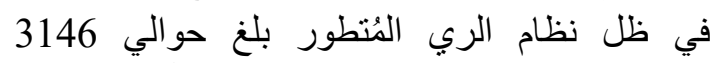
جنيه/فدان، وهو يزيد بمقدار 491 جنيهاً عن نظيره

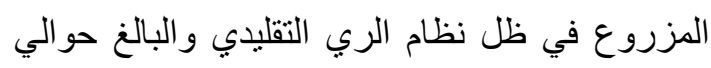

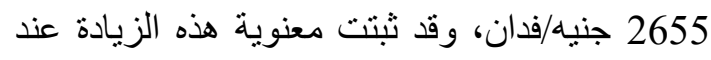

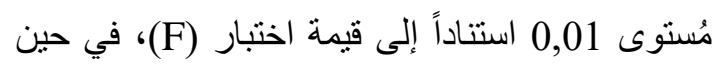

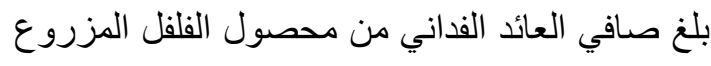

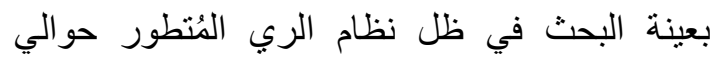
3893 جنيه/فدان، وهو يزيد بمقدار 789 جنيهاً عن الري الرئ نظيره المزروع في ظل نظام الري التقليدي و البالغ

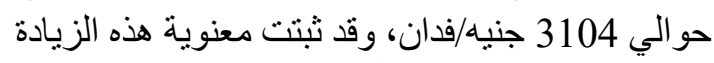

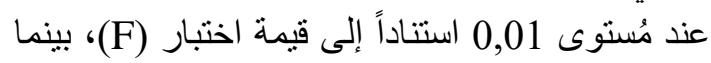

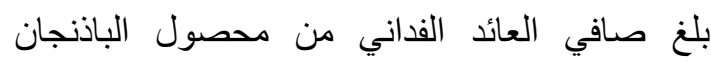
المزروع في ظل نظام الري المُنطور حوالي 3084 جنيه/فدان، وهو يزيد في بمقدار 572 جنيهاً عن نظيره

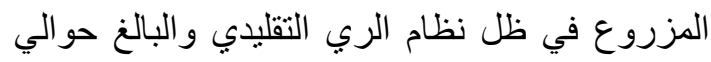

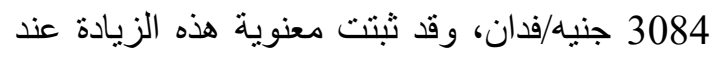

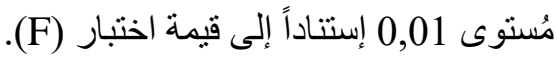

(2) الأربحية النسبية: يتضح من البيانات الواردة

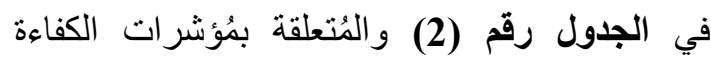

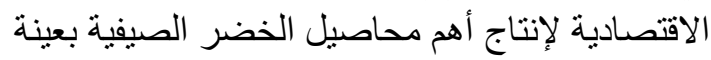
البحث في ظل نُظم الري المُختلفة أن الأربحية النسبية

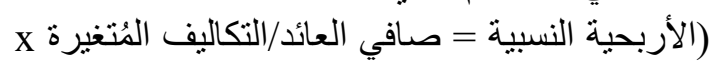
100) لمحصول الكوسة المزروع في ظل نظام الري الري

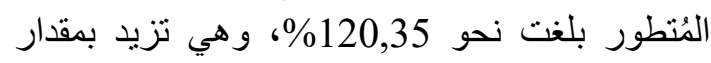

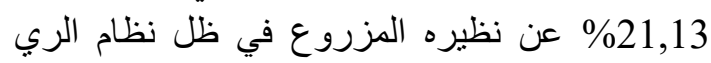

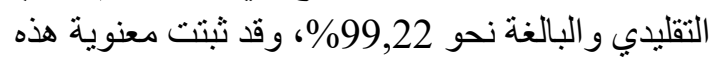
الزيادة عند مُستوى 0,01 استناداً إلى قيمة اختبار 
جدول رقم 2. بعض مُؤشر ات الكفاءة الاقتصادية المُرتبطة بإنتاج أهم محاصيل عينة البحث في ظل نُظم الري

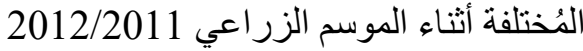

\begin{tabular}{|c|c|c|c|c|c|c|c|c|c|}
\hline \multicolumn{9}{|c|}{ مُؤشرات الكفاءة الاقتصادية } & \multirow{3}{*}{ المحصُول } \\
\hline \multicolumn{3}{|c|}{ مُعدل العُائد على الجنيه } & \multicolumn{3}{|c|}{ الأربحية النسبية } & \multicolumn{3}{|c|}{ (جنيه/فـاني العائد } & \\
\hline 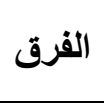 & مُنطور ري & تقليدي ري & 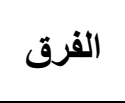 & مُنطور ري & تقليدي & 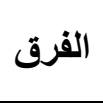 & مُتطور ري & تقليدي ري & \\
\hline *0.15 & 0.85 & 0.70 & ${ }^{*} 21.13$ & 120.35 & 99.22 & *491 & 3146 & 2655 & الكوسة \\
\hline *0.23 & 0.96 & 0.73 & *33.55 & 131.95 & 98.40 & *789 & 3893 & 3104 & 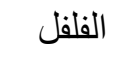 \\
\hline *0.16 & 0.73 & 0.57 & ${ }^{*} 22.73$ & 99.42 & 76.69 & *572 & 3084 & 2512 & الباذنجان \\
\hline
\end{tabular}

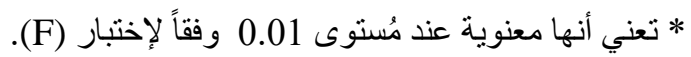
المصدر: جُمتت وحُسبت من البيانات الواردة باستمارة الاستبيان الخاصة بعينة البحث أثناء الموسم الزراعي 2012/2011. في ظل نظامي الري التقليدي، و الري المُتطور.

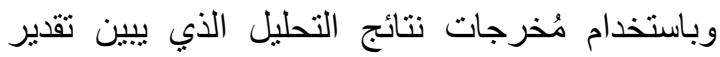
دوال الإنتاج بطريقة (O.L.S) وطريقة (M.L.E)

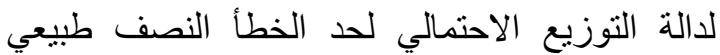

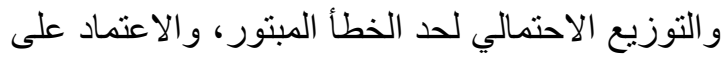

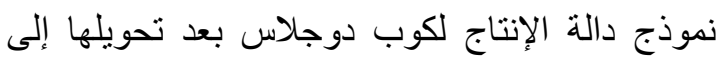
الصُورة اللوغاريتمية المُزدوجة لتقدير دوال الإنتاج الحدودية العشوائية الكمية والقيمية للمحاصيل موضع لئه البحث في ظل نظامي الري التقليدي، و الري المُنطور ، حيث يتكون هذا النمُوذج من مُتغير نابع والمُنمثل في لري كمية إنتاج الفدان من المحصُول موضع البحثث (Y) في حالة تقدير الكفاءة الإنتاجية أو قيمة إنتاج الفدان من الناج

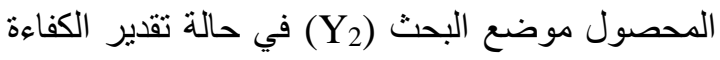

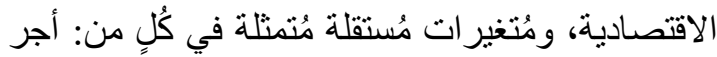
العمل البشري- جنيه/فدان (X1)، وتكلفة العمل الآلي-

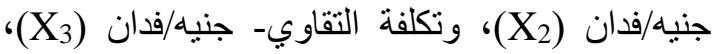

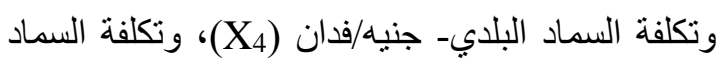

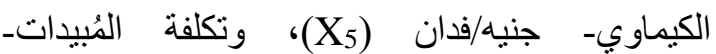

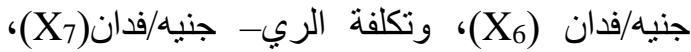

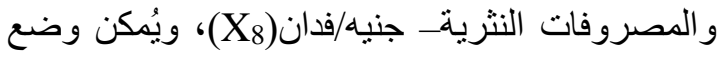

ومما سبق يتضح تفوق مُؤشر ات الكفاءة الاقتصادية لأهم محاصيل الخضر الصيفية بعينة البحث المزروعة فئنة في ظل نظام الري المُنطور عن نظيرنها المزروعة في لهين ظل نظام الري التقليدي، مما يُشير إلى زيادة كفاءة

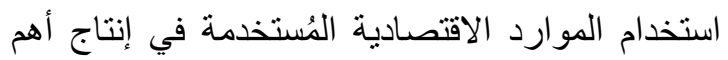
محاصيل الخضر الصيفية في ظل نظام الري المُنطور

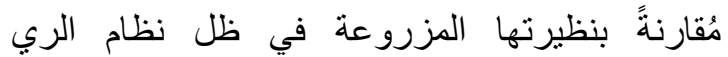
التقليدي، الأمر الذي يتطلب من واضعي السياسة الاقتصادية الزراعية زيادة الاهتمام وتبني فكرة تعميم

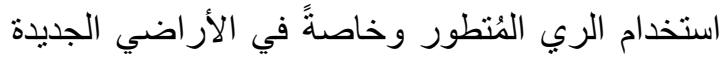
لزيادة الإنتاج الزراعي ومن ثم تخفيف العجز في التي الميزان التجاري، هذا فضلاً عن توفير كميات كبيره من المياه يُمكن استغلالها في زر اعة أر اضي جديدة. ثالثاً: الكفاءة الإنتاجية والاقتصادية لأهم محاصيل الخضر الصيفية بعينة البحث في ظل نُظم الري الرئة المُختلفة يُمكن تقدير الكفاءة الإنتاجية والاقتصادية لأهم محاصيل الخضر الصيفية موضع البحث باستخدام برنامج (Version 4.1 c) التقدير دوال الإنتاج لأهم محاصيل الخضر الصيفية المزروعة 
طبيعي، المبتور إستتاداً إلى قيمة (L.R)، إلا أنه تم الإعنماد على نموذج التوزيع المبتور نظراً لإرتفاع الإنها

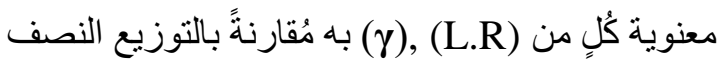
طبيعي، ويتضح من دالة الإنتاج الحدودية العشوائية

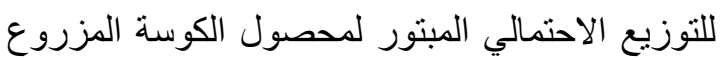
في ظل نظام الري التقليدي أن مرونة كل من تكلفة

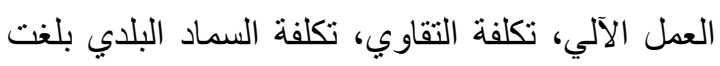

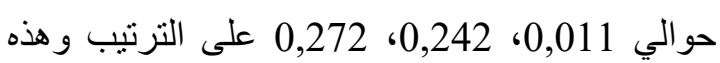

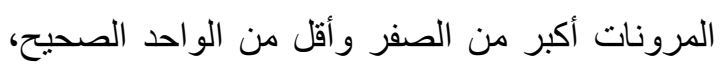

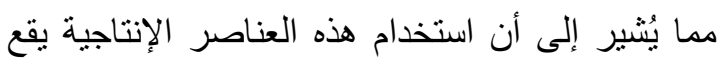

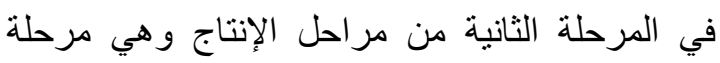

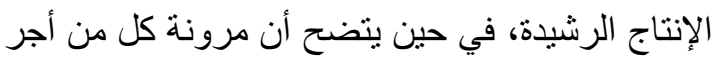

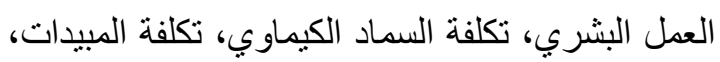

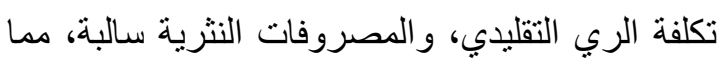
يُشير إلى أن استخدام هذه العناصر الإنتاجية يقع في المرحلة الثالثة من مراحل الإنتاج وهي مرحلة إنتاج

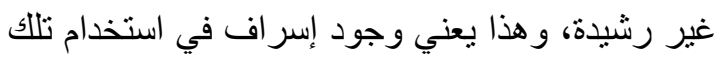
العناصر الإنتاجية ويجب خفض وهض الكميات المُستخدمة

كما يتضح من البيانات الواردة في الجدول رقم (5) لإلئة

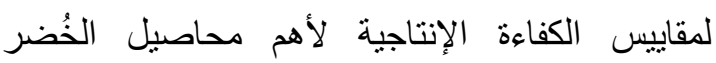

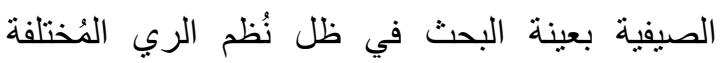

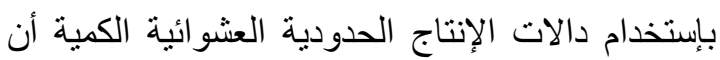

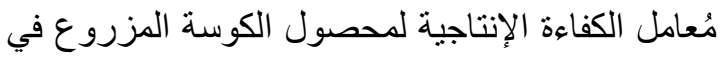
ظل نظام الري التقليدي بلغ نحو 89\%، مما يُشير إلى عالى

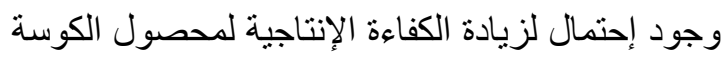

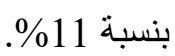

وبإستعر اض مُخرجات التحليل الحُدودي العشو ائي بطريقة (M.L.E) و الواردة في الجدول رقم (4) لنتائج تقدير الكفاءة الإنتاجية لمحصول الكوسة المزروع في الني ظل نظام الري المُتطور بطريقة التحليل الحدودي

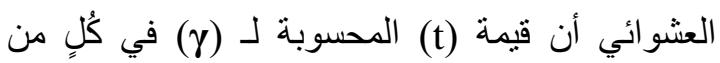

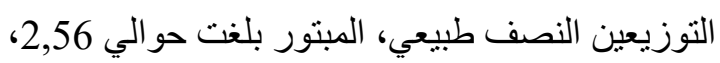
1,41 على الترتيب، في حين بلغت قيمة (t) الجدولية لئية
نمؤذج دالة الإنتاج المُستخدم على الثكل الرياضي

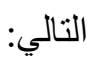
$\operatorname{Ln} \hat{Y}=\operatorname{Ln} \alpha+B_{1} \operatorname{LnX}_{1}+B_{2} \operatorname{Ln} X_{2}+B_{3}$ $\operatorname{Ln} X_{3}+B_{4} \operatorname{Ln} X_{4}+B_{5} \operatorname{Ln} X_{5}+B_{6} \operatorname{Ln} X_{6}$ $+\mathrm{B}_{7} \operatorname{Ln} \mathrm{X}_{7}+\mathrm{B}_{8} \operatorname{Ln} \mathrm{X}_{8}$

$$
\text { حيث تُمثل: }
$$
مرونات اليُتغير ات الاقتصادية المُشار إليها.

(أ) الكفاءة الإنتاجية لأهم محاصيل الخضر الصيفية بعينة البحث في ظل نُظم الري المُختلفة:

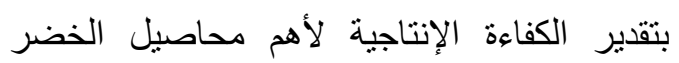

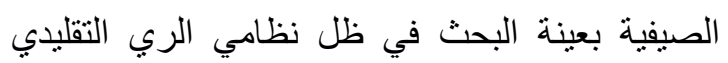

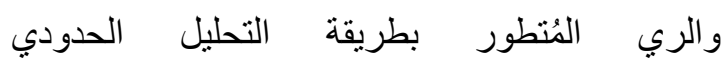
العشو ائي (S.F.A) باستخدام برنامج (SRONTIER بن (Version 4.1 c) النتائج ويُمكن إستعر اضها لكل محصُول من محاصيل عينة البحث على حده فيما يلي:

(1) الكفاعة الإنتاجية لمحصول الكوسة في ظل نُّم الري المُختلفة: بإستعر اض مُخرجات الإنهات التحليل الحُدودي العشوائي بطريقة (M.L.E) و الواردة في الجدول رقم (3) لنتائج تقدير الكفاءة الإنتاجية لمحصول الكولية الكودية المزروع في ظل نظام الري التقليدي بطريقة التحليل

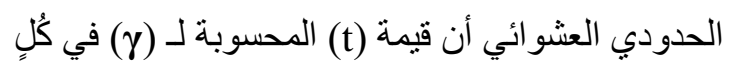
من التوزيعين النصف طبيعي، المبتور بلغت حوالي الي لئي 2,24، 2,98 على الترتيب، وهي أكبر من قيمة (t) الجدولية عند مُستوى 0,05 و التي تُقدر بحو الي 2,04 2,04، مما يُشير إلى قبول عشوائية التوزيعين وعدم الاعتماد

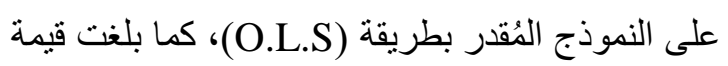

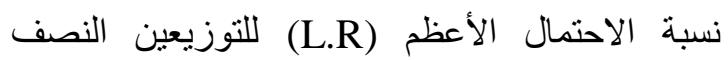
طبيعي، المبتور حوالي 18,34، 22,64 على الترنيب الاعتئ

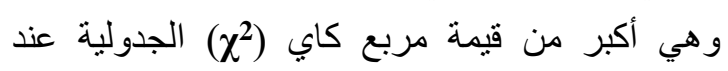

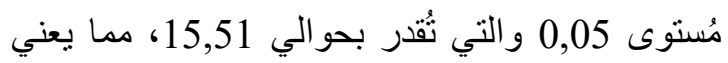
أنه على الرغم من معنوية كل من التوزيعين النصف 
الحُدودي العشوائي بطريقة (M.L.E) و الواردة في الجدول رقم (4) لنتائج تقدير الكفاءة الإنتاجية

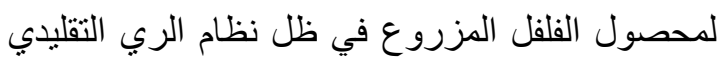

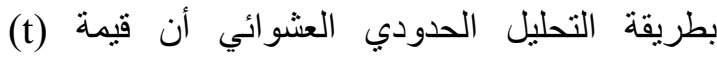

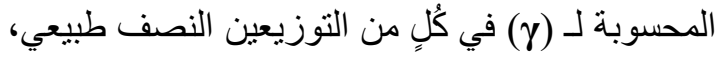
المبنور بلغت حوالي 5,03، 1,38 على الترتيب، في

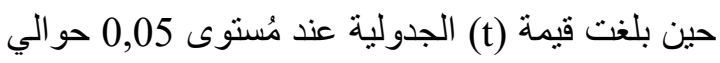

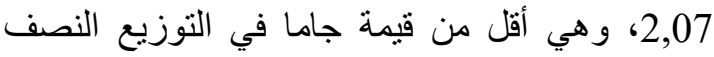

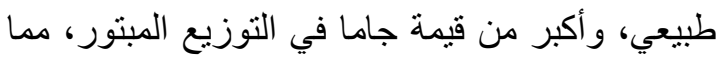

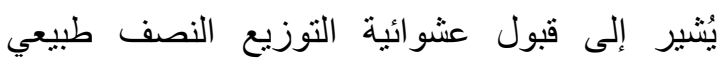

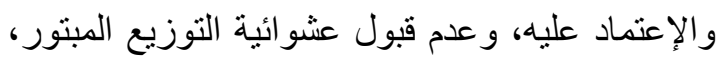

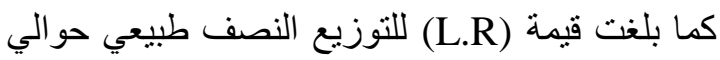
29,14 وهي أكبر من قيمة (X),

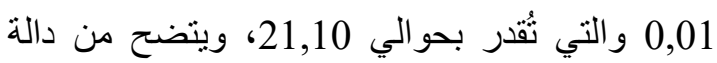

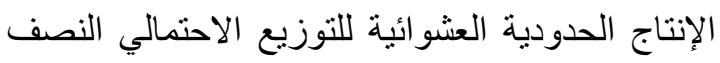

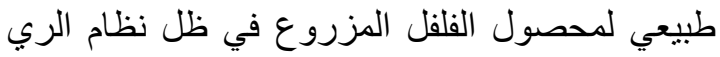

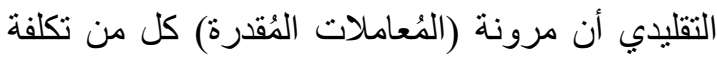

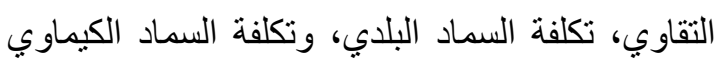
بلغت حوالي 0,146، 0,203، 0,120 على الترتيب و هذه المرونات أكبر من الصفر وأقل من الواحد الصحيح، مما يُشتير إلى أن استخدام هذه العنداص العندر الإنتاجية يقع في المرحلة الثانية من مراحل الإنتاج

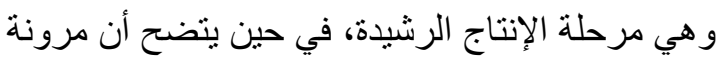
كل من أجر العمل البشري، تكلفة العمل الآلي، تكلفة التئة فئنة

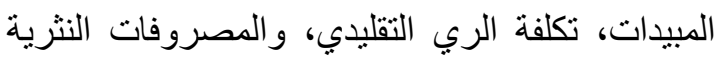

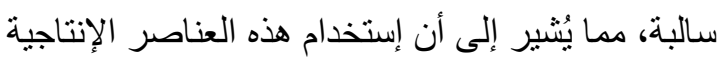
يقع في المرحلة الثالثة من مر احل الإنتاج وهي مرحلة الثناج إنتاج غير رشيدة، وهذا يعني وجود إسراف في في الإني استخدام تللك العناصر الإنتاجية ويجب خفي وهض وجن الكميات المُستخدمة منها.

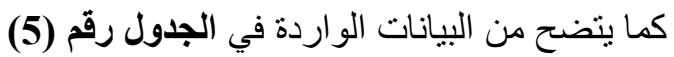

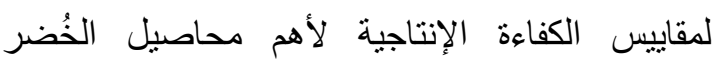

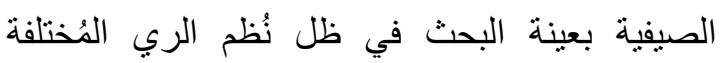
بإستخدام دالات الإنتاج الحدودية العشوائية الكمية أن الن النية
عند مُستوى 0,05 حوالي 2,07، وهي أقل من قيمة جاما في التوزيع النصف طبيعي، و أكبر من قيمة جاما

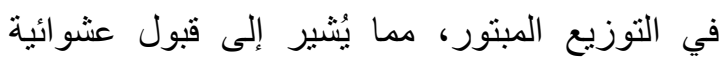
التوزيع النصف طبيعي والإعتماد عليه، وعدم قبول عشوائية التوزيع المبتور، كما بلغت قيمة (L.R)

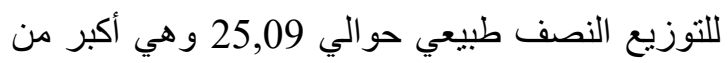

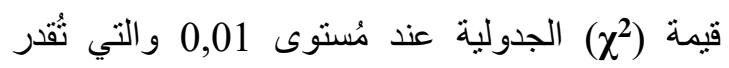
بحوالي 21,10، ويتضح من دالة الإنتاج الحدودية العشو ائية للتوزيع الاحتمالي النصف طبيعي لمحصول

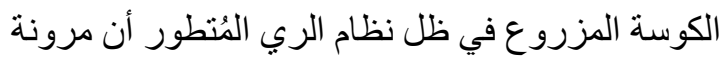

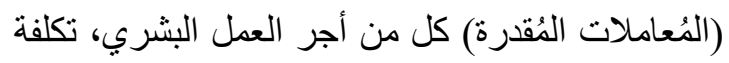

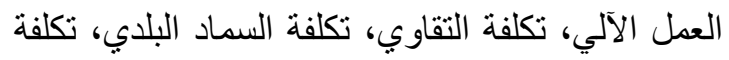
السماد الكيماوي، وتكلفة الري المُتطور بلغت حوالئي 0,021، 0,103، 0,312، 0,305، 0,095، 0,183 على الترتيب وهذه المرونات أكبر من الصفر و أقل من الن الصن

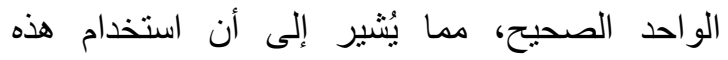

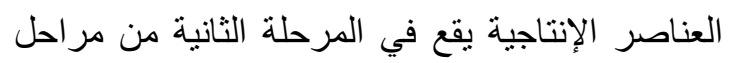

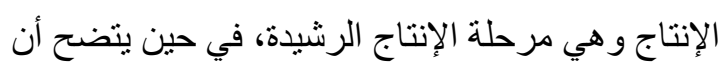
مرونة كل من تكلفة المبيدات، المصروفات النثرية سالبة، مما يُشير إلى أن إستخدام هذه العناصر الإنتاجية

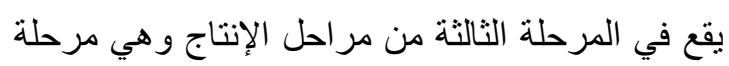
إنتاج غير رشيدة، وهذا يعني وجود إسراف في في الفي استخدام تلك العناصر الإنتاجية ويجب خفض ولثن الكميات

$$
\text { المُستخدمة منها. }
$$

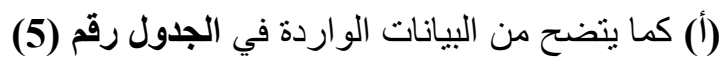

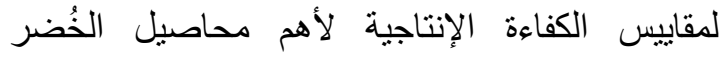

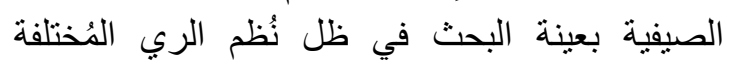

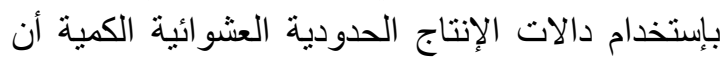

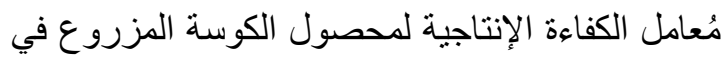

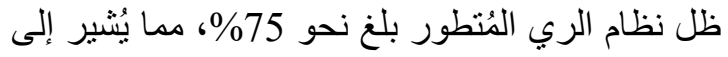
وجود إحتمال لزيادة الكفاءة الإنتاجية لمحصول لفول الكوسة بنسبة 25\%.

(2) الكفاءة الإنتاجية لمحصول القلقل في ظل نُظم

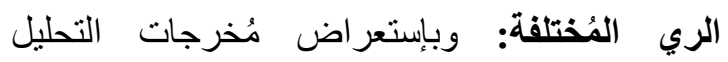


إسر اف في إستخدام هذا العنصر الإنتاجي ويجب خفض الكميات المُستخدمة منه.

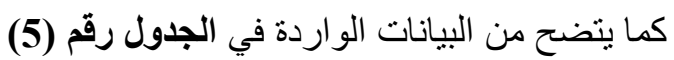

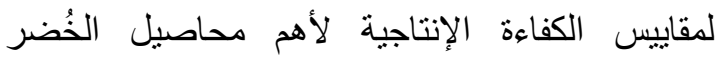
الصيفية بعينة البحث في ظل نُظم الري الئختلفة بإستخدام دالات الإنتاج الحدودية العشوائية الكمية أن

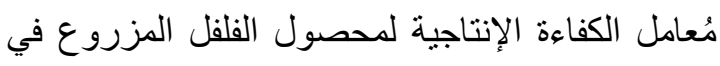
ظل نظام الري المُنطور بلغ نحو 80\%، مما يُشير إلى لى وجود إحتمال لزيادة الكفاءة الإنتاجية لمحصول لكول الفلفل

$$
\text { بنسبة 20\%. }
$$

(3) الكفاعة الإنتاجية لمحصول الباذنجان في ظل نُظم

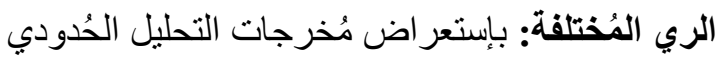
العشو ائي بطريقة (M.L.E) و الو اردة في الجدول رقم (3) لنتائج تقدير الكفاءة الإنتاجية لمحصول الباذنجان المزروع في ظل نظام الري التقليدي بطريقة التحليل

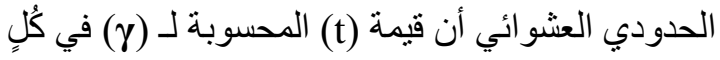
من التوزيعين النصف طبيعي، المبتور بلغت حوالي

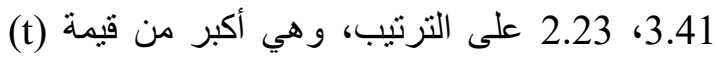

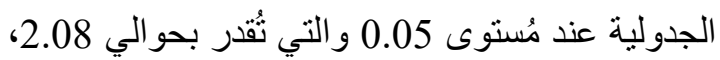
مما يُشير إلى قبول عشوائية التوزيعين و عدم الاعنماد على النموذج الئقدر بطريقة (O.L.S)، كما بلغت قيمة

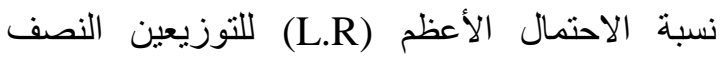

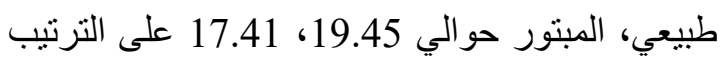

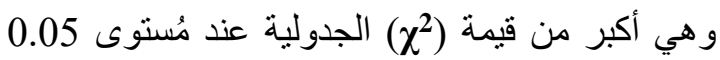
و التي تُقدر بحو الي 15.51، مما يعني أنه على الرغم

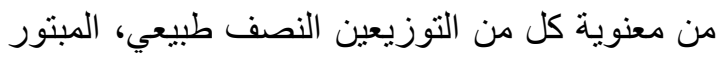

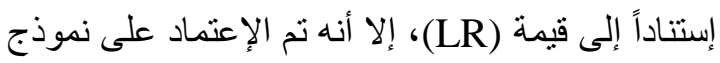
التوزيع النصف طبيعي نظر اً لإرتفاع معنوية كُلٍ من:

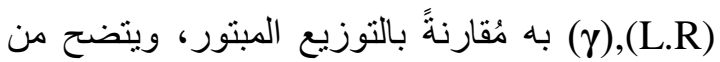
دالة الإنتاج الحدودية العشوائية للتوزيع الاحتمالي لئي

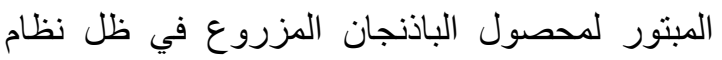

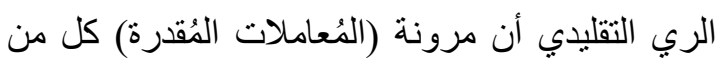
تكلفة التقاوي، تكلفة السماد البلدي، تكلفة السماد الكيماوي، تكلفة الري التقليدي، والمصروفات النية النثرية
مُعامل الكفاءة الإنتاجية لمحصول الفلفل المزروع في

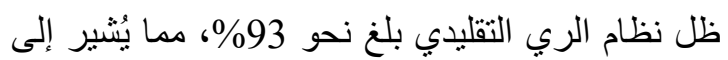

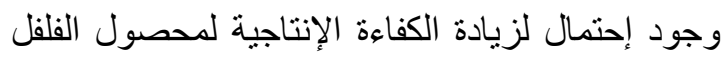
بنسبة 7\% وبإستعر اض مُخرجات التحليل الحُدودي العشوائي بطريقة (M.L.E) و الواردة في الجدول رقم (4) لنتائج تقدير الكفاءة الإنتاجية لمحصول الفلفل المزروع في ظل نظام الري المُنطور بطريقة التحليل الحدودي

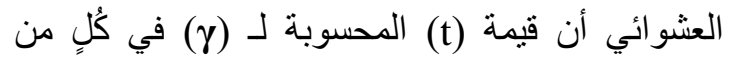

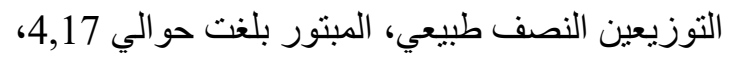
1,98 على الترتيب، في حين بلغت قيمة (t) الجدولية

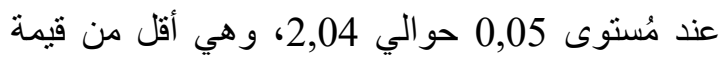
جاما في التوزيع النصف طبيعي، و أكبر من قيمة جاما

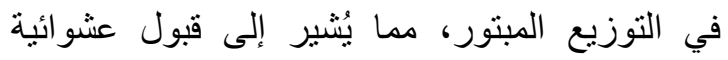
التوزيع النصف طبيعي والإعتماد عليه، وعدم قبول عشوائية التوزيع المبتور، كما بلغت قيمة (L.R) للتوزيع النصف طبيعي حوالي 18,26 و هي أكبر من فن النئ

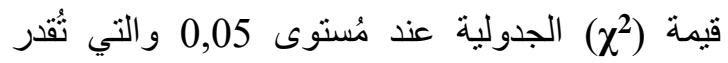
بحوالي 15,51، ويتضح من دالة الإنتاج الحدودية

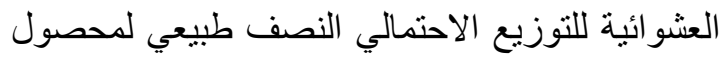

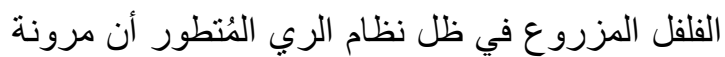

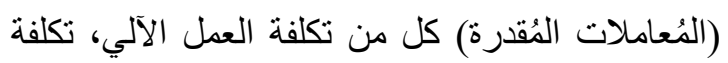
التقاوي، تكلفة السماد البلدي، تكلفة السماد الكيماوي، تكلفة المُبيدات، تكلفة الري المُنطور، والمصروفات

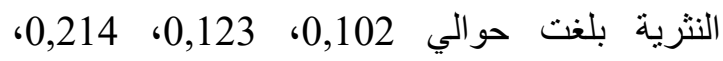
0,138، 0,121، 0,142، 0,024 على الترتيب و هذه المرونات أكبر من الصفر وأقل من الواحد الصحيح،

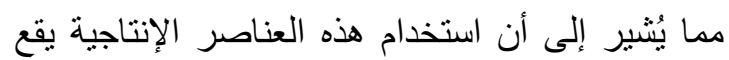

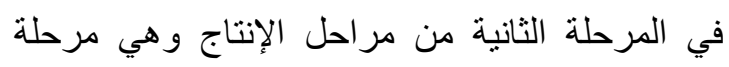

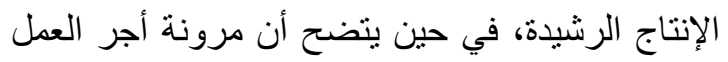

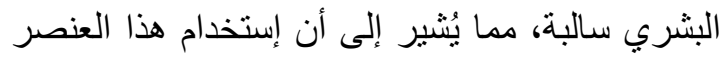
الإنتاجي يقع في المرحلة الثالثة من مراحل الإنتاج

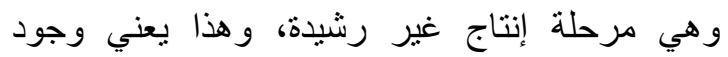


العشوائية للتوزيع الاحتمالي المبتور لمحصول الباذنجان المزروع في ظل نظام الري المُنطور أن النّان

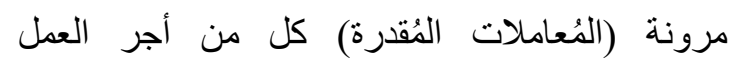
البشري، تكلفة العمل الآلي، تكلفة التقاوي، تكلفة السماد

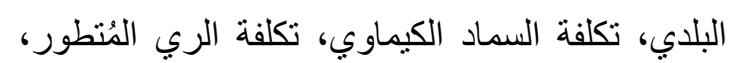

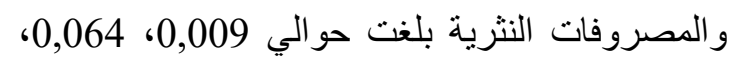

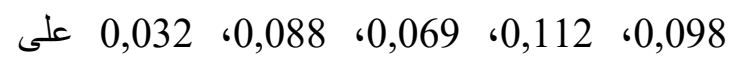
الترتيب ورذه المرونات أكبر من الصفر وأقل من

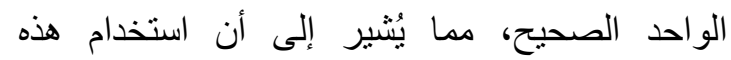

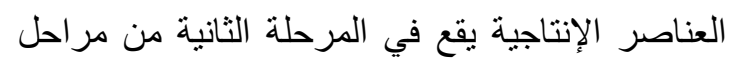

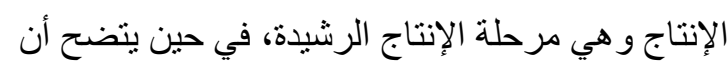

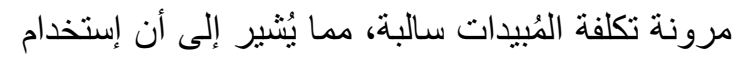
هذا العنصر الإنتاجي يقع في المرحلة الثالثة من مر احل

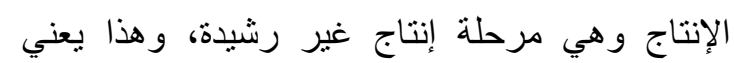

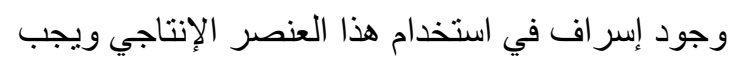
خفض الكميات المُستخدمة منه.

كما ينضح من البيانات الواردة في الجدول رقم (5) لإنة

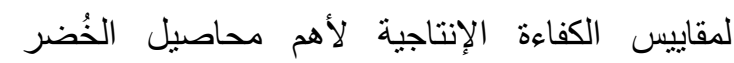

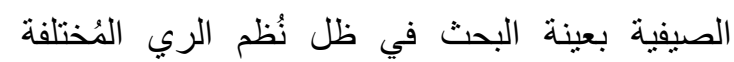

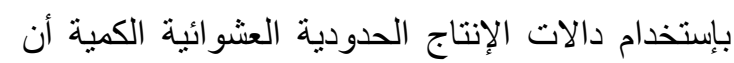

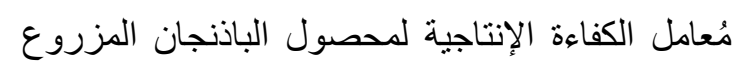

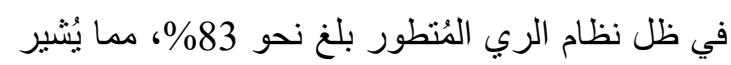

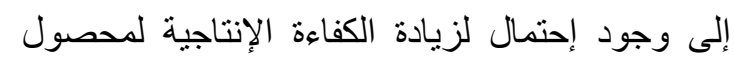
الفلفل بنسبة 17\%.

(ب) الكفاعة الاقتصادية لأهم محاصيل الخضر الصيفية بعينة البحث في ظل نُظم الري المُختلفة

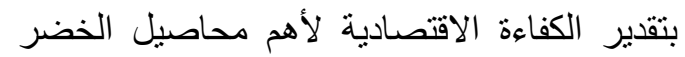

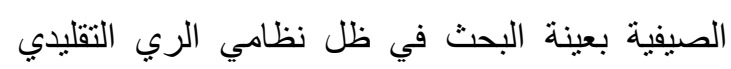

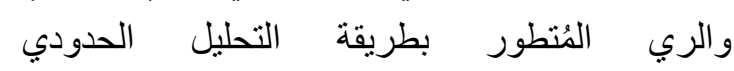
العشو ائي (S.F.A) باستخدام برنامج (Version 4.1 c) النتائج ويُمكن إستعر اضها لكل محصُول من محاصيل عينة البحث على حده فيما يلي:
بلغت حوالي 0,137، 0,041، 0,023، 0,009، 0,004 على الترتيب وهذه المرونات أكبر من الصفر

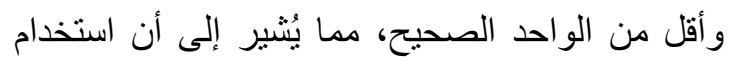

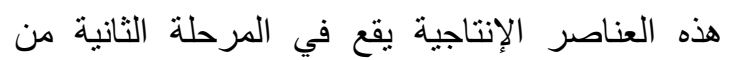

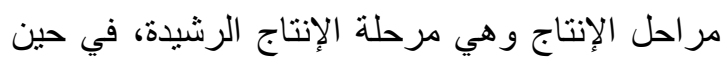

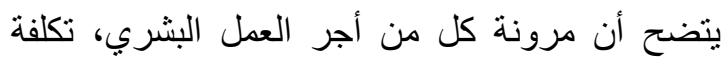

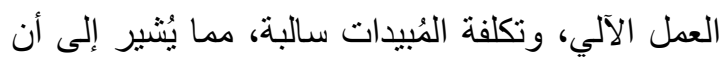
استخدام هذه العناصر الإنتاجية يقع في المرحلة الثالثة

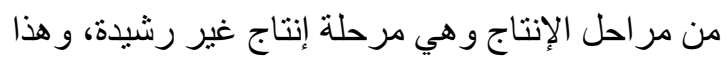
يعني وجود إسر اف في استخدام تلك العناصر الإنتاجية ويجب خفض الكميات المُستخدمة منها.

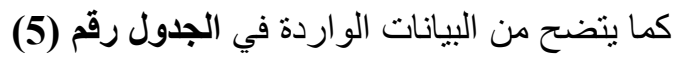

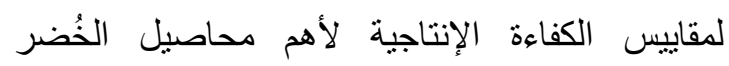

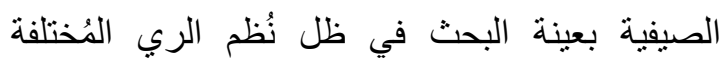

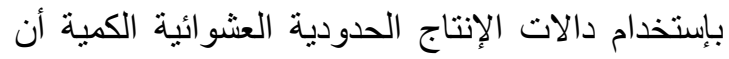

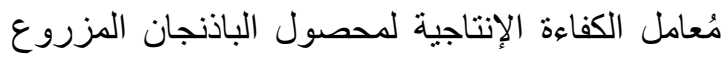

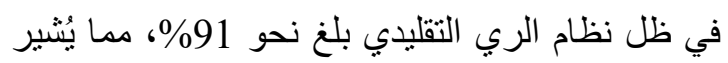

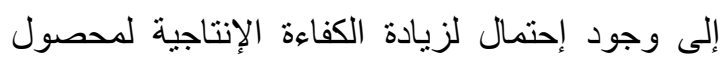

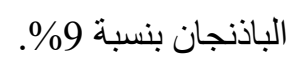
وبإستعر اض مُخرجات التحليل الحُدودي العشو ائي بطريقة (M.L.E) و الواردة في الجدول رقم (4) لنتائج تقدير الكفاءة الإنتاجية لمحصول الباذنجان المزروع في الوداري

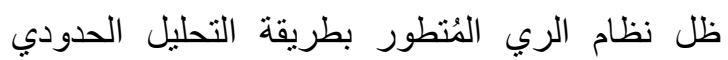

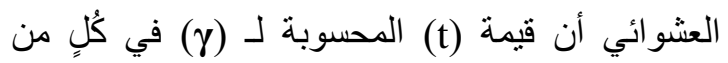

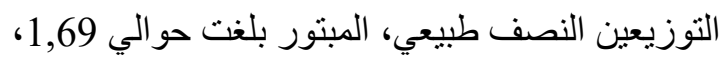
5,35 على الترتيب، في حين بلغت قيمة (t) الجدولية

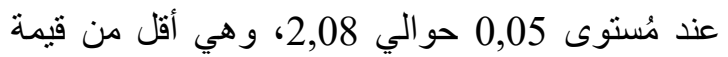

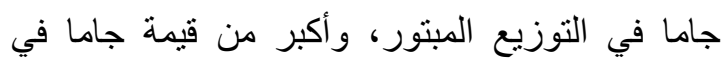

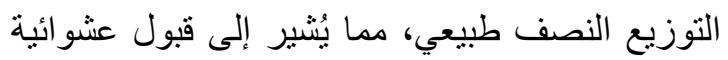

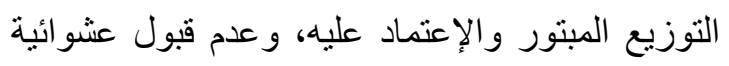
التوزيع النصف طبيعي، كما بلغت قيمة (L.R)

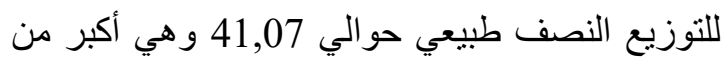

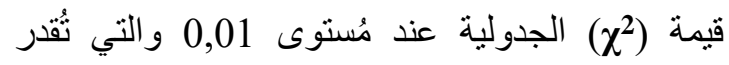
بحوالي 21,10، ويتضح من دالة الإنتاج الحدودية 
قاسم ، السنتريسى ، الدناصوري

Arab Univ. J. Agric. Sci., 22(2), 2014 
جدول رقم 5. مقاييس الكفاءة الإنتاجية لأهم محاصيل الخضر الصيفية بعينة البحث في ظل نُظم الري المُختلفة

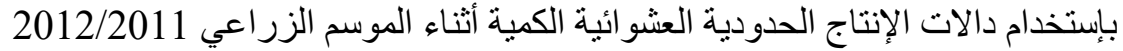

\begin{tabular}{|c|c|c|c|}
\hline $\begin{array}{c}\text { مُعامل الكفاعة الإنتاجية } \\
\text { (\%) } \\
\text { (\%) }\end{array}$ & نوع التوزيع & نظام الري & المحصول \\
\hline $\begin{array}{l}89 \\
75\end{array}$ & $\begin{array}{c}\text { Truncated } \\
\text { Half- Normal }\end{array}$ & تقلقيدي & الكوسة \\
\hline $\begin{array}{l}93 \\
80 \\
\end{array}$ & $\begin{array}{l}\text { Half- Normal } \\
\text { Half- Normal }\end{array}$ & تُقليدي & الفلفل \\
\hline $\begin{array}{l}91 \\
83\end{array}$ & $\begin{array}{c}\text { Half- Normal } \\
\text { Truncated }\end{array}$ & تقنيدي & الباذنجان \\
\hline
\end{tabular}

FRONTIER (Version 4.1 c) المصدر: جُمعت وحُسبت من تحليل البيانات الواردة بالإستمارة البحثية بإستخدام برنامج

.(Coelli, 1996)

بلغت حوالي 0,093، 0,108، 0,0820

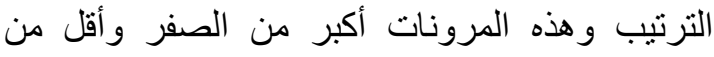

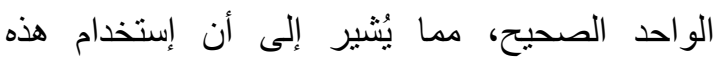

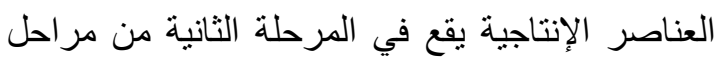

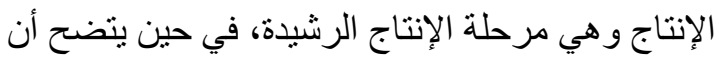

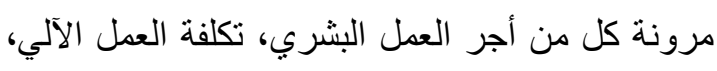

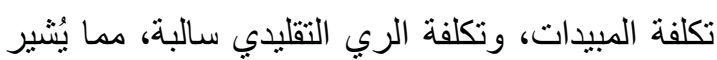

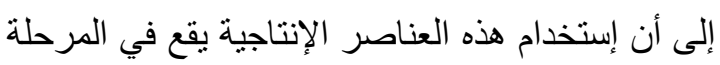

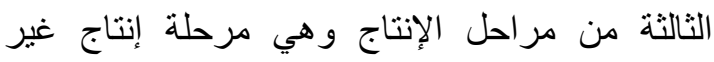
رشيدة، وهذا يعني وجود إسراف في إستخدام تللك الإن العناصر الإنتاجية ويجب خفض وهن الكميات المُستخدمة

كما يتضح من البيانات الواردة في الجدول رقم (8)

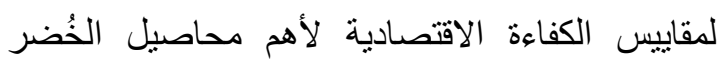

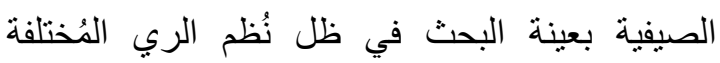

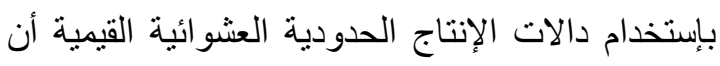

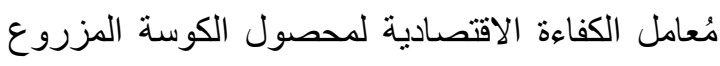

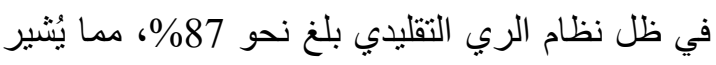

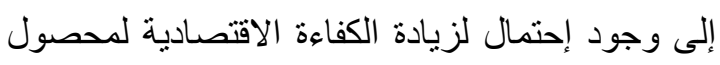

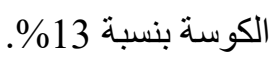

(1) الكفاءة الاقتصادية لمحصول الكوسة في ظل نُظم الري المُختلفة: بإستعر اض مُخرجات التحليل التحاديل الحُدودي

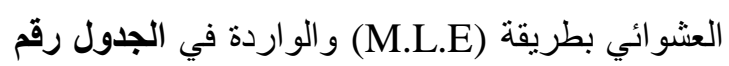
(6) لنتائج تقدير الكفاءة الاقتصادية لمحصول الكوسة المزروع في ظل نظام الري التقليدي بطريقة التحليل

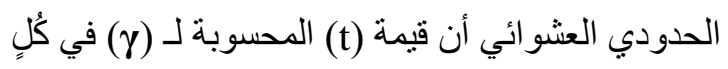

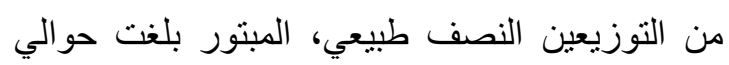

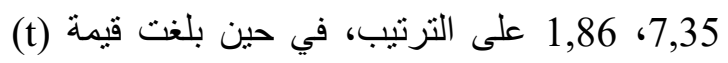

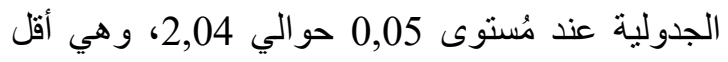

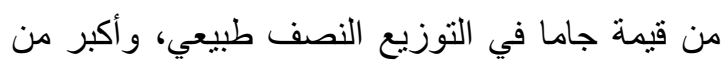

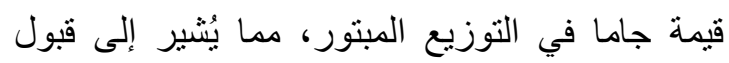
عشو ائية التوزيع النصف طبيعي والإعتماد عليه، و عدم قبول عشوائية التوزيع المبتور، كما بلغت قيمة (L.R)

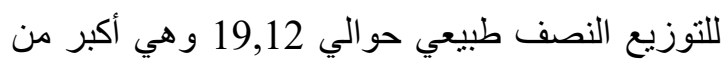

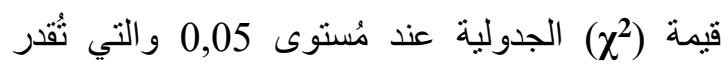
بحوالي 15,51، ويتضح من دالة الإنتاج الحدودية

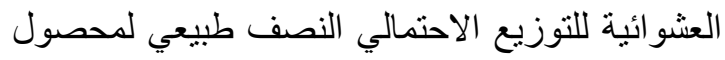

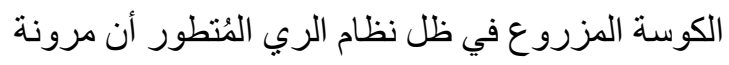

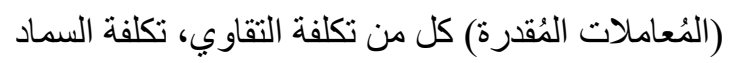

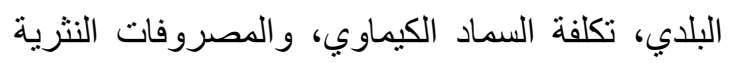


(أ) كما يتضح من البيانات الواردة في الجدول رقم (8)

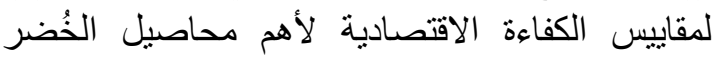

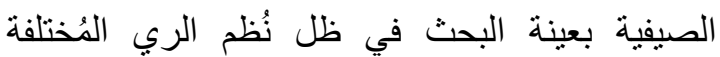

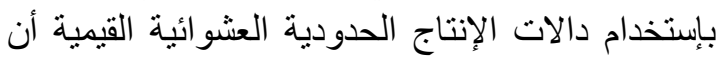

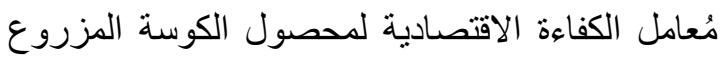

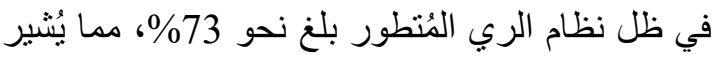

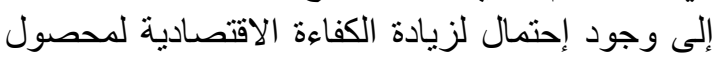
الباذنجان بنسبة 27\% و

(2) الكفاعة الاقتصادية لمحصول الفلفل في ظل نُظم

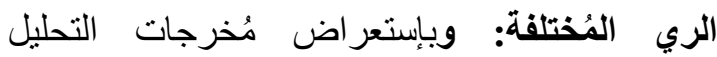
الحُدودي العشوائي بطريقة (M.L.E) و الواردة في الجدول رقم (6) لنتائج تقدير الكفاءة الاقتصادية لمحصول الفلفل المزروع في ظل نظام الري التقليدي بطريقة التحليل الحدودي العشوائي أن قيمة (t)

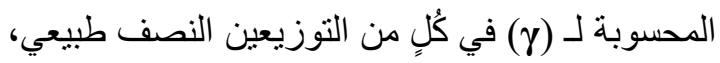

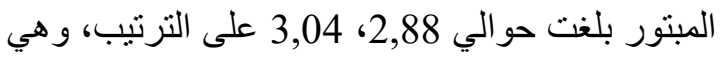
أكبر من قيمة (t) الجدولية عند مُستوى

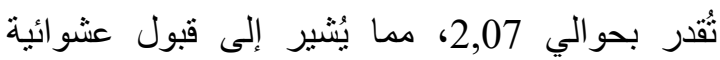
التوزيعين و عدم الاعتماد على النموذج اليُقدر بطريقة

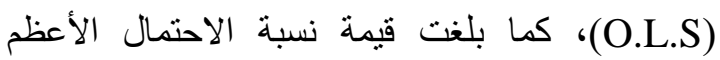
(L.R)

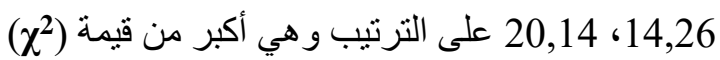

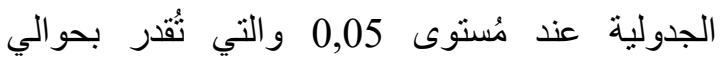

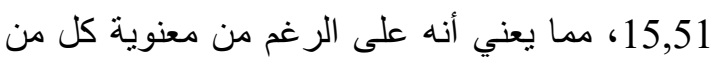

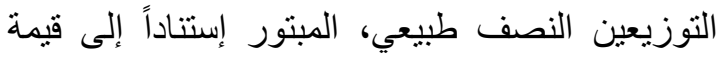

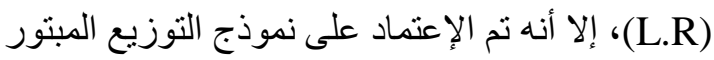

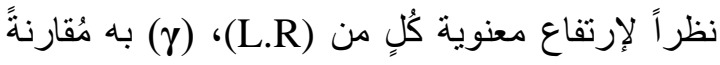
بالتوزيع النصف طبيعي. ويتضح من دالة الإنتاج

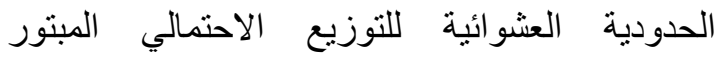
لمحصول الفلفل المزروع في ظل نظام الري التقليدي التئي

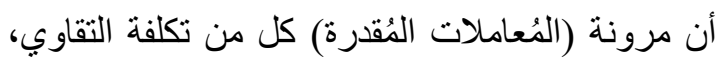

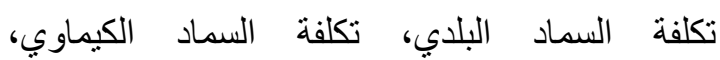
و المصروفات النثرية بلغت حوالي 0,123، 0,234، 0,118، 0,081 على الترتيب وهذه المرونات أكبر من الصفر وأقل من الواحد الصحيح، مما يُشير إلى أن
وبإستعر اض مُخرجات التحليل الحُدودي العشوائي بطريقة (M.L.E) و الواردة في الجدول رقم (7) لنتائج تقدير الكفاءة الاقتصادية لمحصول الكوسة المزروع في ظل نظام الري المُنطور بطريقة التحليل الحدودي العيل

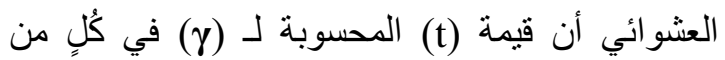
التوزيعين النصف طبيعي، المبتور بلغت حوالي 2,22، 3,19 على الترنيب، وهي أكبر من قيمة (t) الجدولية

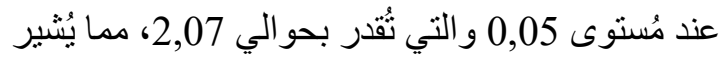

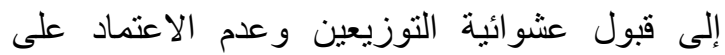
النموذج الئقدر بطريقة (O.L.S)، كما بلغت قيمة نسبة

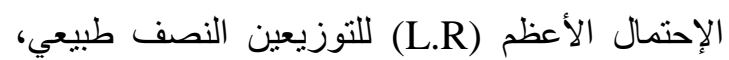

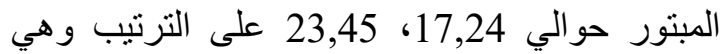

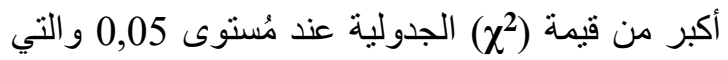

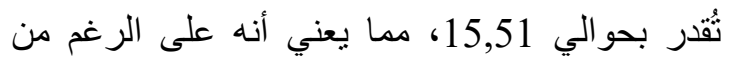
معنوية كل من التوزيعين النصف طبيعي، المبتور

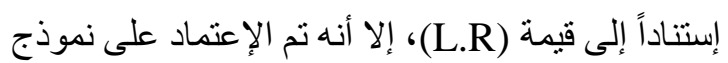

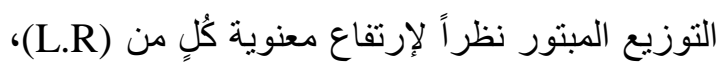

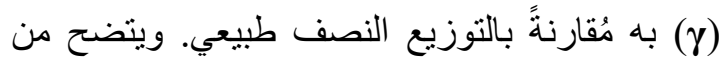

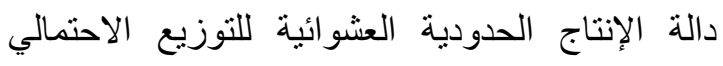

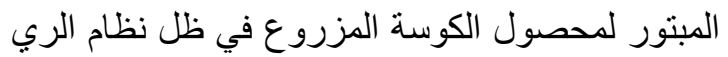

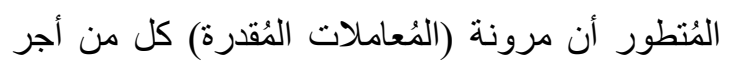

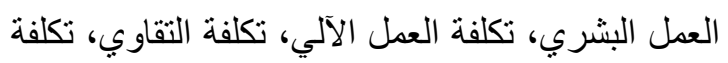
السماد البلدي، تكلفة السماد الكيماوي، تكلفة الري، الرئ المُتطور بلغت حوالي 0,0840، 0,065، 0,112، 0,118، 0,098، 0,169 على الترتيب وهذه المرونات

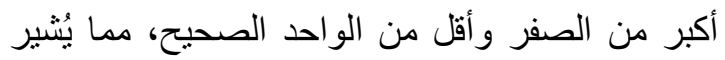

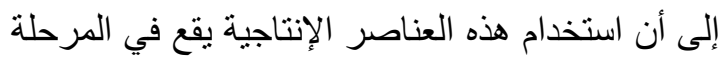

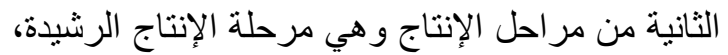

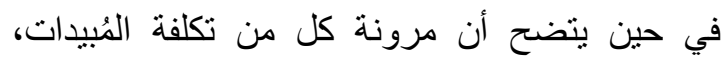
و المصروفات النثرية سالبة، مما يُشير إلى أن إستخدام

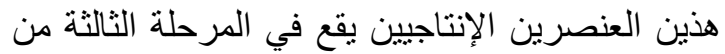
مراحل الإنتاج وهي مرحلة إنتاج غير رشيدة الإني، وهذا

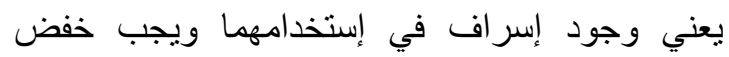
الكميات المُستخدمة منها. 
به مُقارنةً بالتوزيع المبنُور. ويتضح من (y)(L.R)

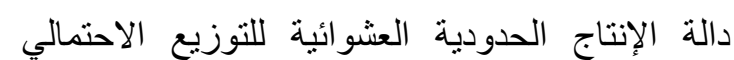

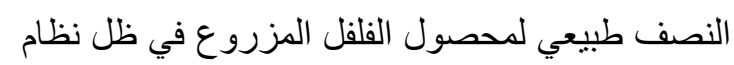

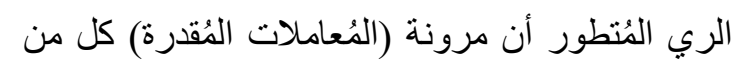

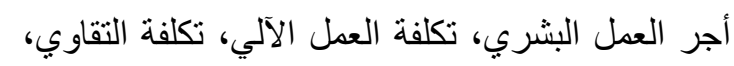

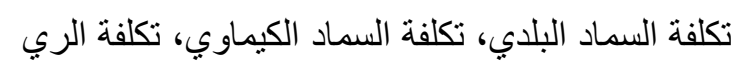

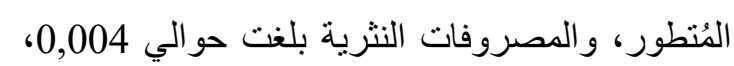
0,006، 0,126، 0,183، 0,136، 0,121، 0,016 على الترتيب وهذه المرونات أكبر من الصفر و أقل من

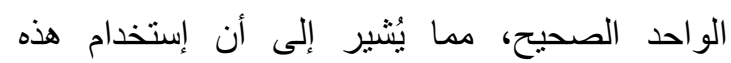

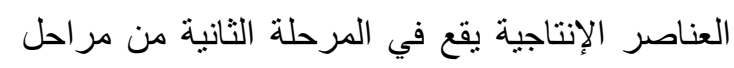

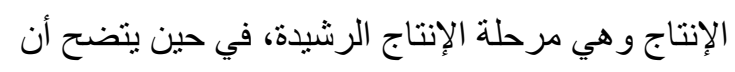

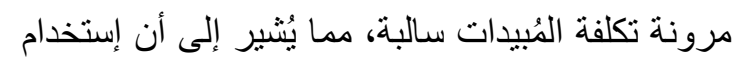

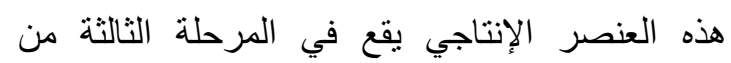

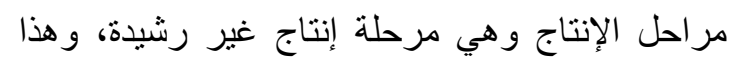
يعني وجود إسراف في إستخدام هذا العنصر الإنتاجي ويجب خفض الكميات المُستخدمة منه.

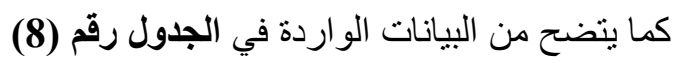

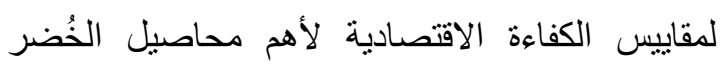

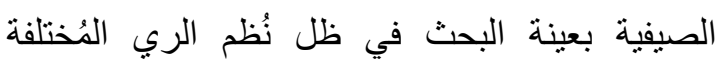

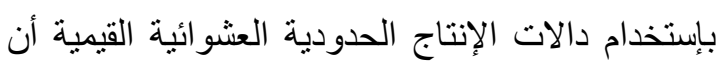

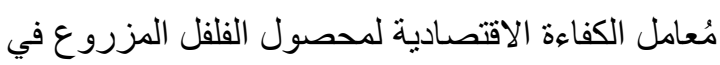

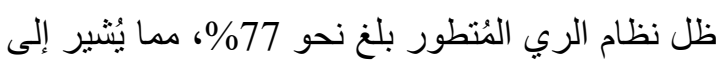

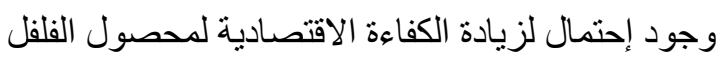
بنسبة 23\%.

(3) الكفاءة الاقتصادية لمحصول الباذنجان في ظل

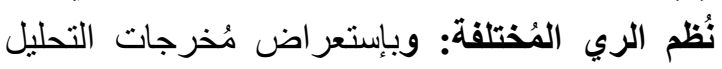

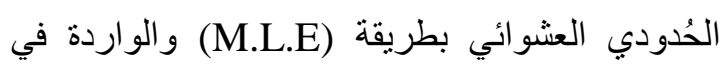
الجدول رقم (6) لنتائج تقدير الكفاءة الاقتصادية

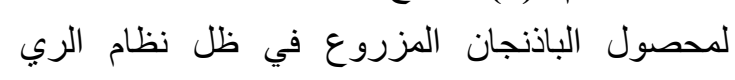

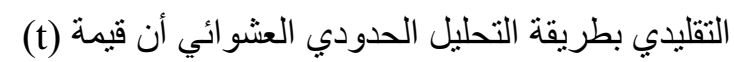

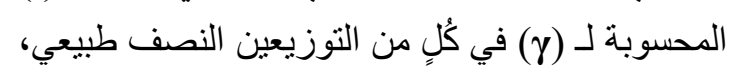

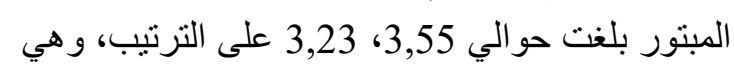

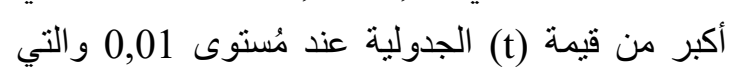

إستخدام هذه العناصر الإنتاجية يقع في المرحلة الثانية

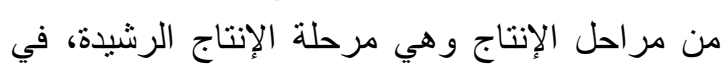

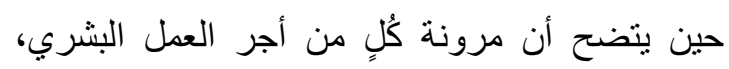

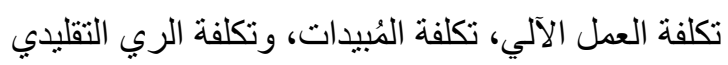

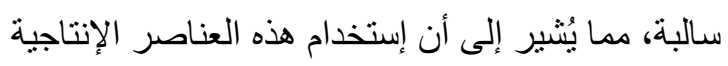

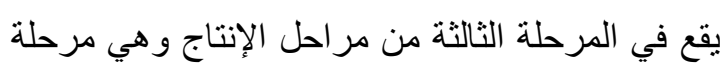
إنتاج غير رشيدة، وهذا بعني وجود إسراف في في

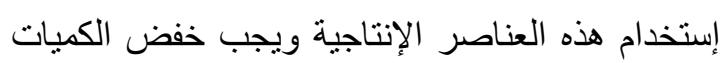
المُستخدمة منها.

كما يتضح من البيانات الواردة في الجدول رقم (8)

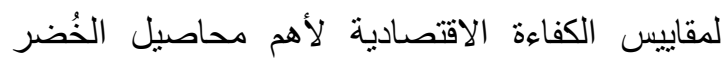

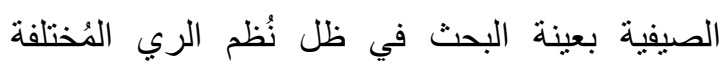

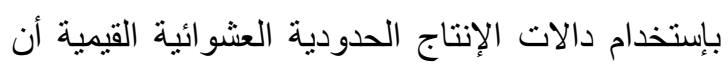

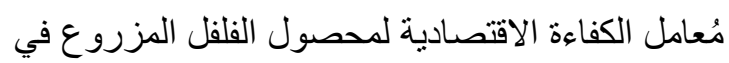

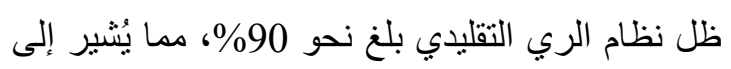

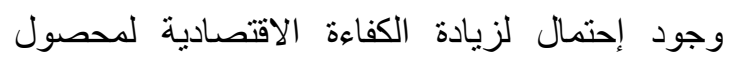

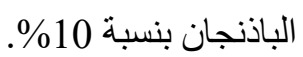
وبإستعر اض مُخرجات التحليل الحُدودي العشو ائي بطريقة (M.L.E) و الو اردة في الجدول رقم (7) لنتائج تقدير الكفاءة الاقتصادية لمحصول الفلفل المزروع في في في لطولي

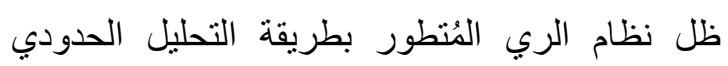

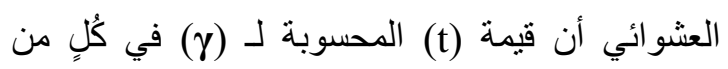

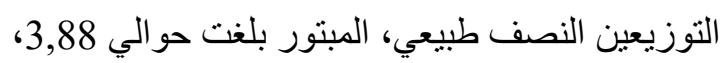
2,51 على الترنيب، وهي أكبر من قيمة (t) الجدولية

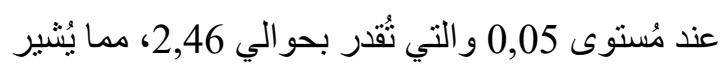

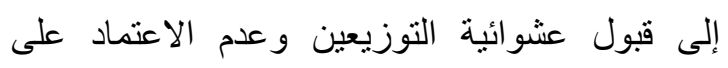
النموذج الئقدر بطريقة (O.L.S)، كما بلغت قيمة نسبة الأبة الاحتمال الأعظم (L.R) للتوزيعين النصف طبيعي، المبتور حوالي 19,54، 16,98 على الترنيب ولئ وهي

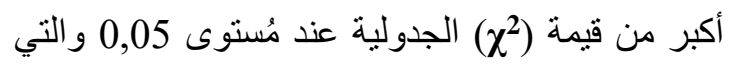

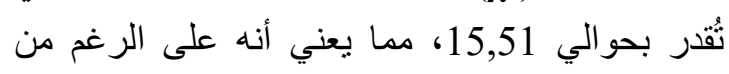

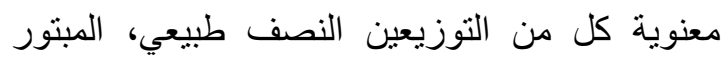

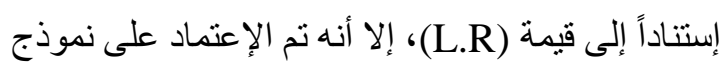

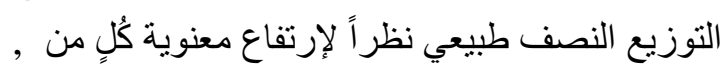


إلى وجود إحتمال لزيادة الكفاءة الاقتصادية لمحصول

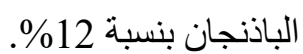
وبإستعر اض مُخرجات التحليل الحُدودي العشوائي بطريقة (M.L.E) و الواردة في الجدول رقم (7) لنتائج

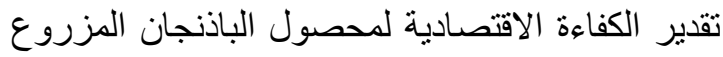
في ظل نظام الري المُنطور بطريقة التحليل الحدودي التئي

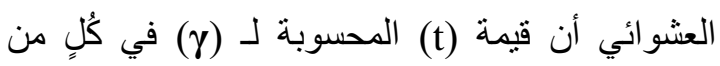

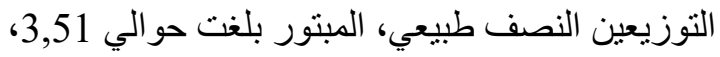
2,31 على الترتيب، وهي أكبر من قيمة (t) الجدولية لئية

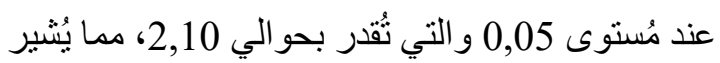

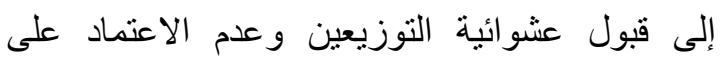

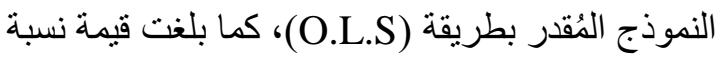
الاحتمال الأعظم (L.R) للتوزيعين النصف طبيعي، المبتور حوالي 27,14، 21,69 على الترنيب وهي الاعني أكبر من قيمة (x) الجدولية عند مُستوى 0,05 و التي

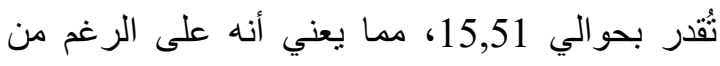

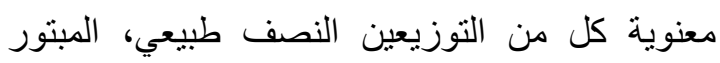

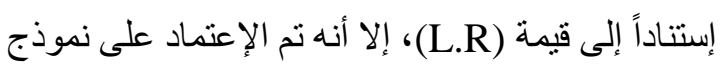

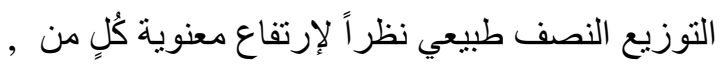

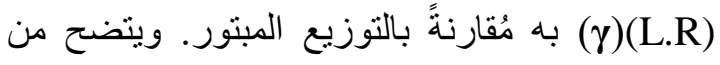

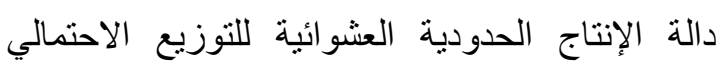
النصف طبيعي لمحصول الباذنجان المزروع في ظل الإنل

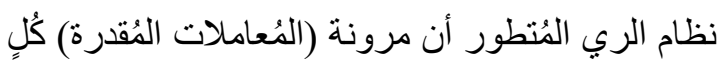
من أجر العمل البشري، تكلفة العمل الآلي، تكلفة

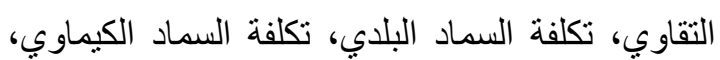
وتكلفة الري المُتطور، و المصروفات النثرية بلغت لئن

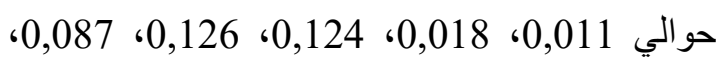
0,131، 0,092 على الترتيب و هذه المرونات أكبر من الصفر وأقل من الواحد الصحيح، مما يُشير إلى ألى أن

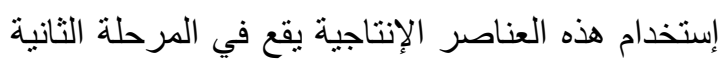

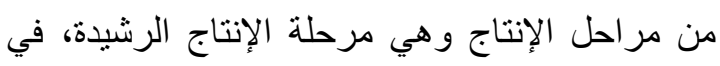

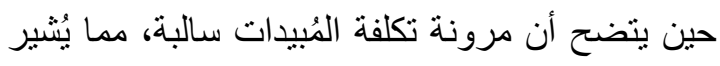
إلى أن إستخدام هذا العنصر الإنتاجي يقع في المرحلة لئل

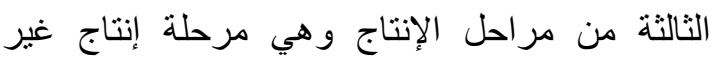

ثُقدر بحوالي 2,52، مما يُشير إلى قبول عثوائية التوزيعين و عدم الاعتماد على النموذج المُقدر بطريقة

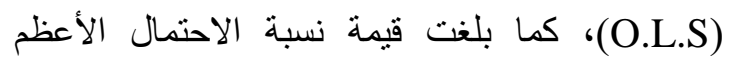
اللتوزيعين النصف طبيعي، المبتور حوالي (L.R)

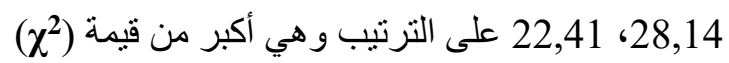

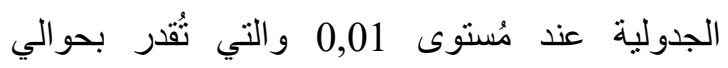

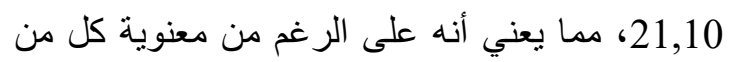

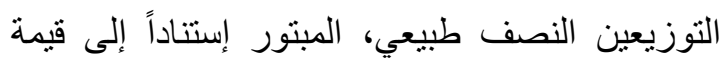

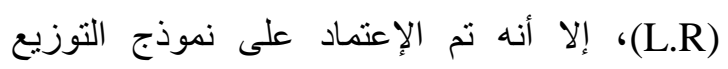

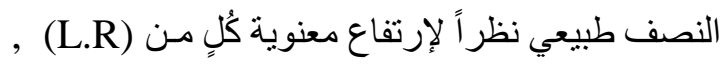

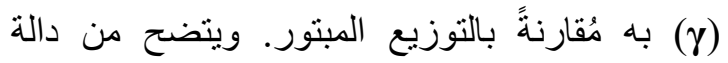

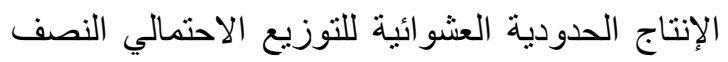

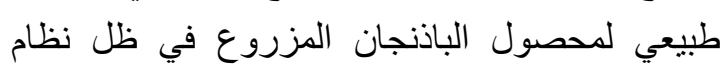

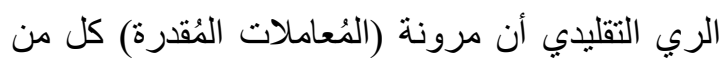

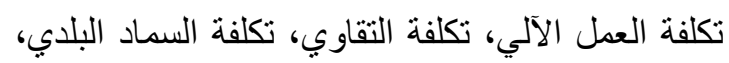

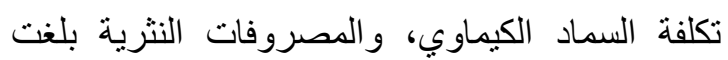
حوالي 0,003، 0,142، 0,088، 0,054، 0,006 على الترتيب وهذه المرونات أكبر من الصفر وأقل من الصن

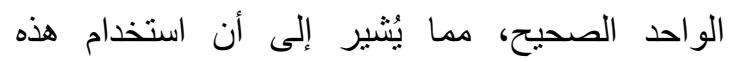

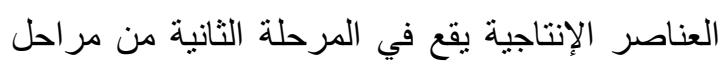

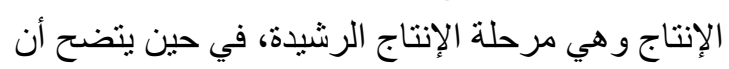

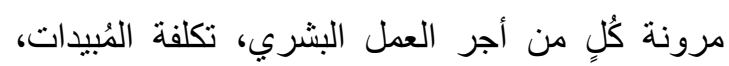
وتكلفة الري التقليدي سالبة، مما يُشير إلى أن استخدام

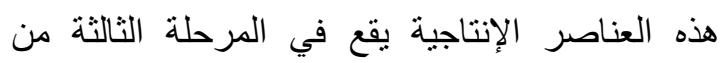
مراحل الإنتاج وهي مرحلة إنتاج غير رشيدة، وهذا لئنا يعني وجود إسراف في استخدام هذه العناصر الإنتاجية ويجب خفض الكميات المُستخدمة منها. كما يتضح من الييانات الواردة في الجدول رقم (8)

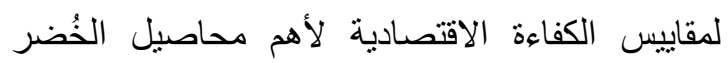

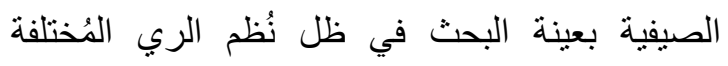

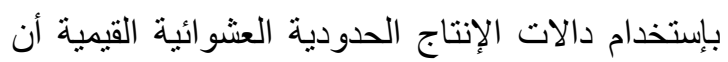

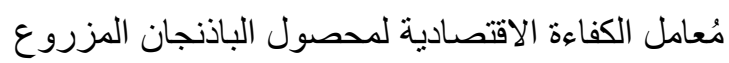

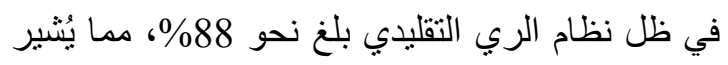


قاسم ، السنتريسى ، الدناصوري

رشيدة، وهذا يعني وجود إسر اف في إستخدام هذا منه. العنصر الإنتاجي ويجب خفض وهض الكميات المُستخدمة 
قاسم ، السنتريسى ، الدناصوري

Arab Univ. J. Agric. Sci., 22(2), 2014 
جدول رقم 8. مقاييس الكفاءة الاقتصادية لأهم محاصيل الخضر الصيفية بعينة البحث في ظل نُظم الري المُختلفة بإستخدام دالات الإنتاج الحدودية العشو ائية القيمية أثناء الموسم الزر الهي اعي

\begin{tabular}{|c|c|c|c|}
\hline معامل الكفاءة الاقتصادية & نوع التوزيع & نوع الري & المحصول \\
\hline $\begin{array}{l}87 \\
73\end{array}$ & $\begin{array}{c}\text { Half- Normal } \\
\text { Truncated } \\
\end{array}$ & التُليدي & الكوسة \\
\hline $\begin{array}{l}90 \\
77\end{array}$ & $\begin{array}{c}\text { Truncated } \\
\text { Half- Normal }\end{array}$ & المُنقور & الفلفل \\
\hline $\begin{array}{l}88 \\
79\end{array}$ & $\begin{array}{l}\text { Half- Normal } \\
\text { Half- Normal }\end{array}$ & التُلتيليدي & الباذنجان \\
\hline
\end{tabular}

FRONTIER (Version 4.1 c) المصدر: جُمعت وحُسبت من تحليل البيانات الواردة بالإستمارة البحثية بإستخدام برنامج

.(Coelli, 1996)

السياسة الاقتصادية الزر اعية إلى زيادة الإهتمام وتبنى

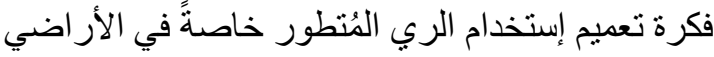
الجديدة لزيادة الإنتاج الزراعي ولتخفيف العجز في العيامي

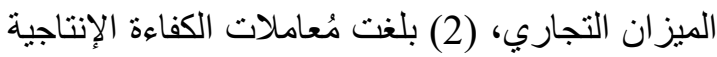

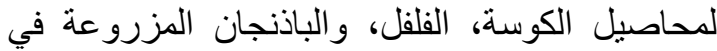
ظل نظام الري المُنظور نحو 75\%، 80\%، 83\%،

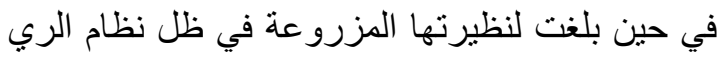
التقليدي نحو 89\%، \%3\%، 91\%، مما يُشير إلى أن فرص محاصيل الخضر المزروعة في ظل نظام الري

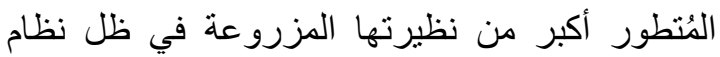

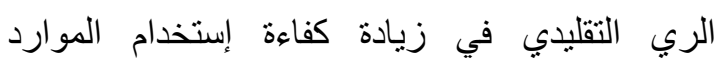
الإنتاجية، (3) بلغت فُعاملات الكفاءة الاقتصادية

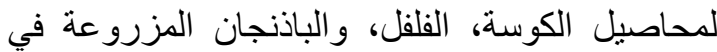
ظل نظام الري المُنظور نحو 73\%، 77\%، 79\%،

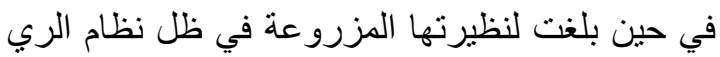
التقليدي نحو 87\%، 90\%، 88\%، مما يُشير إلى أن فرص محاصيل الخضر المزروعة في ظل نظام الري

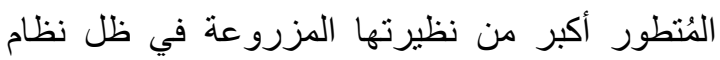
الري التقليدي في زيادة كفاءة إستخدام الموارد الاقتصادية وتحقيق مكاسب اقتصادية.

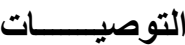

كما يتضح من البيانات الواردة في الجدول رقم (8) لمقاييس الكفاءة الاقتصادية لأهم محاصيل الخُضر

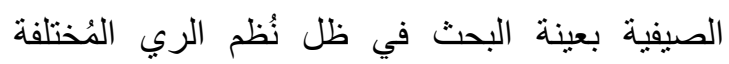
بإستخدام دالات الإنتاج الحدودية العشوائية القيمية أن فئن

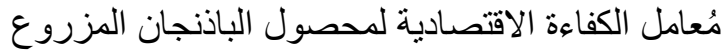
في ظل نظام الري المُتنطور بلغ نحو 79\%، مما يُشنير

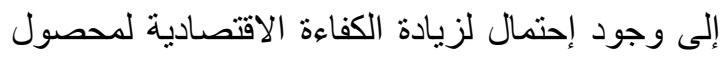

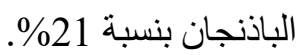

\section{النتائج البحثية}

توصل البحث إلى مجموعة من النتائج المُرتبطة بأثر تطبيق نُظم الري المُختلفة على الكفاءة الإنتاجية والاقتصادية لأهم محاصيل الخضر الصيفية بالأراضي لإي

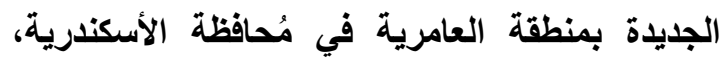
ويُمكن إستعراض أهم هذه النتائج فيما يلي: (1)

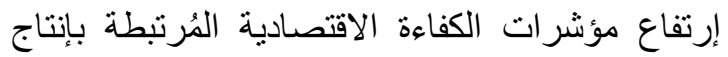
أهم محاصيل الخضر الصيفية بعينة البحث المزروعة

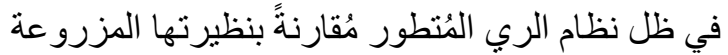

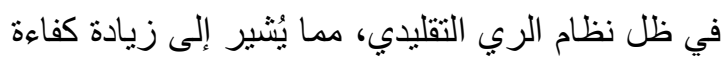

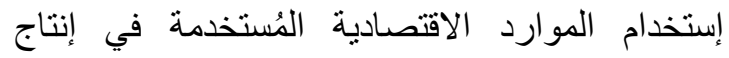
محاصيل الخضر في ظل استخدام الري المُنطور

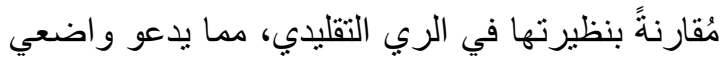


و التكنولوجيـــــــا، المجالس النوعية، نوفمبر

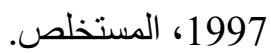

الاناصوري، محمد فوزي محمد- دراسة اقتصادية

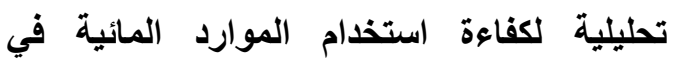
الأراضي الجديدة (دراسة ميدانية بمنطقة البستان

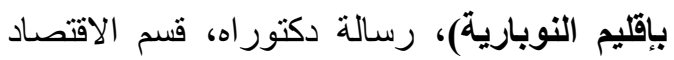

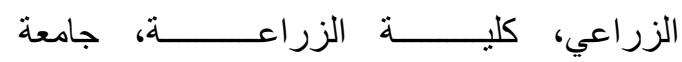

الإسكندرية، الزعية 2007.

الصفتي، محمد فوزي- دراسة تحليلية اقتصادية

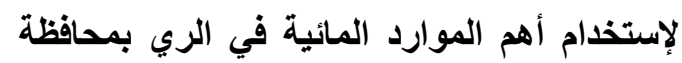

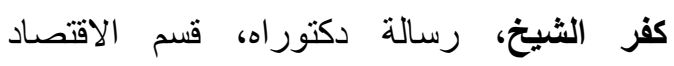
الزراعي، كلية الزر اعة بكفر الثيخ، جامعة طنطا،

2004

مديرية الزراعة بالأسكندريةــ مركز المعلومات ودعم

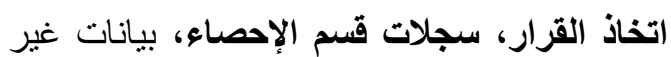

$$
\text { منشورة، } 2012 .
$$

شافعي، محمود عبد الهـــادي - مشـــروع تحسين

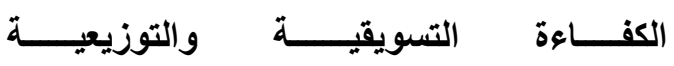
والتصنيعية للمحاصيل الزراعية، أكاديمية البحث ولثئه

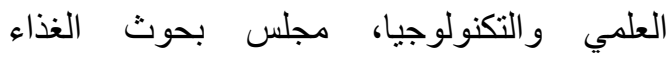
والزر اعة والري، شعبة الاقتصاد الزراعي وتتمية

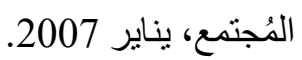

هنادي مُصطفى عبد الراضي - تقدير الكفاعة الفنية لمزارع القمح بمنطقة البُستان بإستخدام المنهجية

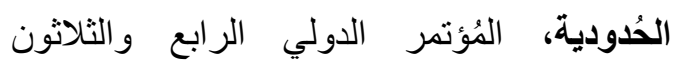
للإحصاء و علوم الحاسب وتطبيقاتها، 5-16 أبريل

وزارة الزراعة واستصلاح الأراضي - قطاع الشئون

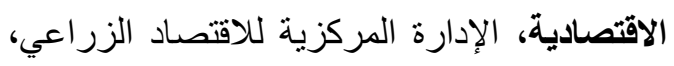

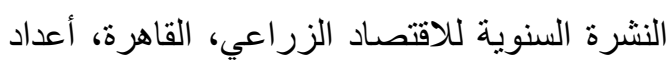

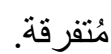

وزارة الموارد المائية والري ـ قطاع التخطيط، بيانات غير منشُورة، القاهرة، 2002. ثانياً: مراجع باللغة الإنجليزية
وفي ضوء ما توصل إليه البحث من نتائج، فإنه

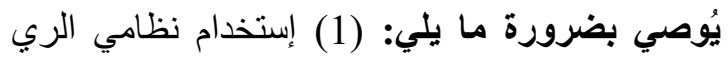

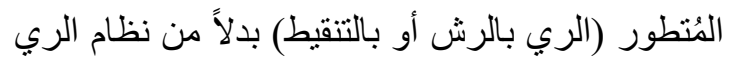

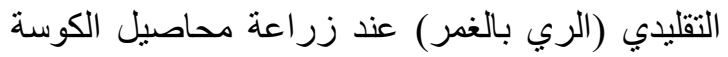
و الفلفل والباذنجان، (2) زيادة فعالية جهاز الإرشاد التراد

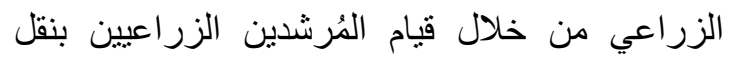
توصيات البحوث للمز ارعين وتدريبهج وزيادة خبر اتهم وتثنجيعهم للاتجاه نحو استخدام نظم الري المُتطور في ولثي

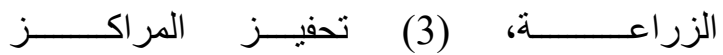

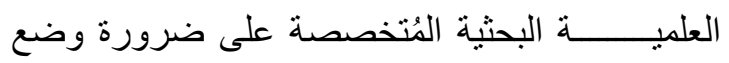

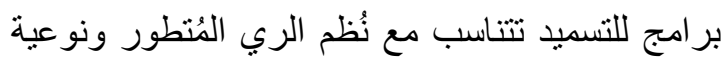

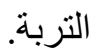

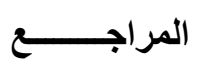

أولاً: مراجع باللغة العربية ناصف، إيمان عطيةـ آليات رفع كفاءة إستخدام مياه الري في الزراعة المصرية، مجلة كلية التجارة

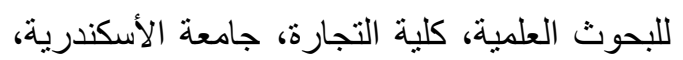

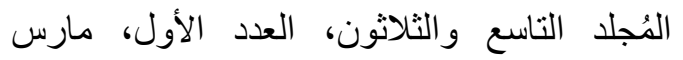
.2002

عبد العال، حمادة عبد الحميد ، سهير محمد فتحي حافظ دراسة تحليلية لبعض أنماط الاستغلال المزرعي لبعض محاصيل الخضر (الطماطم لئل

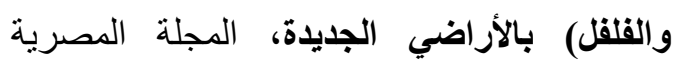

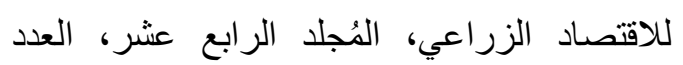
الأول، مارس 2004، المستخلص. راضي، محمد عبد الهادي وآخرون- مشروع تقييم نُظم الري الحديثة في الأراضي الرملية والجيرية، ولهي

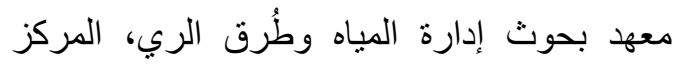

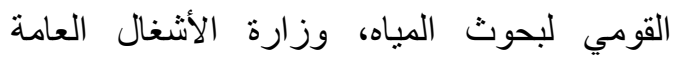

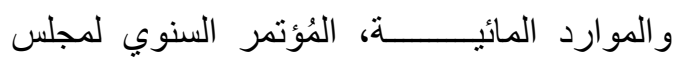

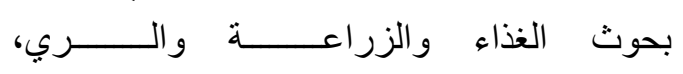

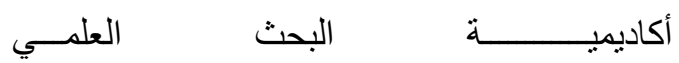


Economic, Review 13, 1972.

Aigner, D.J., C.A.K. Lovell and P. Schmidt - Formulation and Estimation of Stochastic Frontier Production Function Models, Journal of Econometrics, 1977.

Awadalla, S., Y. PI, - Rising the Economical Productivity of New Lands Through maximing The Profitability from agricultural wastes , National Research Project (NARP) GR, Final Report, 1994.

Chen, Z.A., E.W. Huffman, and S. Rozelle, - Technical Efficiency of Modern Grain Production on Chinese Farms: A Stochastic Production Frontier Approach, Labor and Human Resource Workshop, Department of Economics, Iowa State University, USA, 2003.

Coelli, T.J., S. Rahman, and C. ThirtleTechnical, Allocative, Cost and Scale Efficiency In Bangladesh Rice Cultivation: A Non-Parametric Approach", Journal of Agricultural Economics, 53, 2002, 607-626.

Farrell, M.J.- The measurement of production efficiency, J. Roy. Statistic. Soc., Ser. A Part 2, 1957.

Kebede, A.T.- Farm Household Technical Efficiency: A Stochastic Frontier Analysis (A Study of Rice Producers in Mardi Watershed in the Western
Afriat S.- Efficiency Estimates of Production Functions, International Development, Region of Nepal, A Masters Thesis, Department of Economics and Social Sciences, Agricultural University of Norway, June 2003.

Pascual, U.- Soil Degration and technical efficiency in Shifting cultivation: the case of Yucatan, Mexico. Technical report, the center for comparative research, Yale university, New Haven, 2001.

Tim Coelli- A Guide to DEAP Version 2.1 : A Data Envelopment Analysis Program, Centre for Efficiency and Productivity Analysis, Department of Econometrics, University of New England, 1996.

Yen-Shogn C.- Frontier Production Approaches for Measuring Efficiency of Egyptian Farms, Degree of Doctor, Graduate Division, University of California, 2002.

$$
\text { ثالثاً: مراجع من الشبكة الدولية للمطلومات }
$$

http://agecon.lib.umn.edu/cgibin/detailview.pl http://econpapers.repec.org/paper/bonbonedp/ bgse125f2006.htm

http://www.economicsnetwork.ac.uk/cheer/ch 151/dea.htm

http://www.unisit.it/ateneo/ricerca/cipa/welco me.htm 